\title{
Physical and Mental Health Consequences of Obesity in Women
}

\author{
Julia Weschenfelder, Jessica Bentley and \\ Hubertus Himmerich \\ Additional information is available at the end of the chapter
}

http://dx.doi.org/10.5772/intechopen.73674

\begin{abstract}
Obesity and overweight are major health concerns and the leading preventable cause of death in developed and developing countries. Obesity affects men and women differently due to biological, socioeconomic, cultural and country-specific gender-related disparities. This book chapter outlines obesity as a risk factor for physical diseases and mental health disorders in women. Obesity has been shown to contribute to the risk of certain types of cancer, including breast, endometrial, gallbladder, oesophageal and renal cancer. In terms of reproductive health, obesity negatively affects both fertility and contraception. In addition, obesity is associated with early miscarriage, higher rates of caesarean section and high-risk obstetrical conditions, in addition to higher maternal and neonatal mortality rates, and congenital malformations. In terms of mental health, obesity is closely linked to depression, anxiety disorders, neurodegenerative diseases and sleep disorders. Socioeconomic, psychosocial and behavioural factors, factors associated with ageing, mechanisms related to the microbiome, gastrointestinal and vascular system, intracellular pathophysiology and metabolism in the body, hormones, adipocytokines and problems associated with medical treatment are important factors linking obesity with its negative consequences on physical and mental health.
\end{abstract}

Keywords: obesity, women, women's health, gender differences, sex hormones, menopausal status, cancer, metabolic syndrome, diabetes, vascular disease, osteoarthritis, reproductive health, fertility, pregnancy, psychiatric diseases, depression, posttraumatic stress disorder, dementia, insomnia 


\section{Introduction}

\subsection{Obesity is related to major health issues in women}

In $2016,13 \%$ of the world's population ( $15 \%$ of women and $11 \%$ of men) was affected by obesity, which is characterised by excess body fat with a Body Mass Index (BMI) $\geq 30 \mathrm{~kg} / \mathrm{m}^{2}$. Obesity and overweight (BMI $\geq 25 \mathrm{~kg} / \mathrm{m}^{2}$ ) are a major health concern, and the leading preventable cause of death in developed and developing countries. Obesity leads to severe impairment of health in both genders [1]. However, obesity may pose a gender-specific risk to the development of comorbidities [2], and can be considered as both an influencing and resulting factor of at least seven of the top 10 health issues in women published by the World Health Organisation (WHO) in 2015: Cancer, reproductive health, maternal health, human immunodeficiency virus infection, other sexually transmitted infections, violence against women, mental health, non-communicable diseases, being young and getting older [3], because obesity is associated with breast and cervical cancer, sexual, reproductive and maternal health issues, developmental and ageing difficulties, mental health disorders, and non-communicable diseases, including obesity itself and its metabolic consequences.

Obesity has been consistently shown to increase rates of breast cancer in postmenopausal women, and is associated with poorer survival rates and increased likelihood of recurrence [4-6]. In addition, a systematic review reported a positive correlation between BMI and endometrial, gallbladder, oesophageal adenocarcinoma and renal cancer in women [7]. In terms of reproductive health, obesity negatively affects both fertility and contraception due to hormonal and metabolic alterations, including hyperinsulinemia and hyperleptinemia, insulin resistance (IR) and hyperandrogenism [8,9]. One of the most common reproductive disorders in women of childbearing age, and the leading cause of infertility, is polycystic ovarian syndrome (PCOS), which can be impaired or even caused by visceral obesity [10]. Maternal health has been reported to worsen as a result of obesity or abnormal weight gain during pregnancy [11-13]. Obesity is related to early loss of pregnancy, higher rates of caesarean (c-) section and high-risk obstetrical conditions, in addition to higher maternal and neonatal mortality rates and congenital malformations $[8,14-16]$. As one of the most common mental health problems in women, according to the $\mathrm{WHO}$, depression is closely linked to obesity in a vicious cycle $[17,18]$. In general, poor socioeconomic status, low income and experience of violence are gender-specific risk factors for common mental health disorders in women, including depression, anxiety, posttraumatic stress disorder (PTSD) and dementia, which also promote obesity [18-20]. Low-grade systemic inflammation deriving from adipose tissue (AT) also appears to be a major factor contributing to the pathophysiology of type II diabetes mellitus (DM II), metabolic syndrome (MS) and cardiovascular diseases (CVD), in addition to the above-mentioned psychiatric disorders [21-24].

\subsection{Specific aspects of obesity in women}

Obesity affects men and women differently due to biological, socioeconomic, cultural and gender-related disparities. Sex hormones have a marked impact on metabolism by modulating the production and effects of hormones and cytokines in the AT, which are important messenger molecules of the immune system [25, 26]. Sex hormones steer patterns of fat distribution. Men 
usually exhibit visceral fat accumulation, which is considered to be metabolically unhealthy, whereas fat accumulates subcutaneously in women. However, the fat distribution in women is influenced by menopausal status, with several studies consistently showing that the prevalence of MS in women increases alongside post-menopausal changes in sex hormone production [27].

In addition to the above, women appear to be more likely than men to develop MS as a response to work stress and low socioeconomic status [2]. In developing countries with more often conservative societies, more women have a sedentary lifestyle than men, and performing physical activity (PA) in public areas is more restricted in women. Despite westernisation, obesity is often a more culturally accepted body image in these countries. Additionally, women may have different food preferences to men, as they tend to consume more foods high in added sugars, refined carbohydrates and energy density. At present, there is a higher availability of these types of food due to the economic growth of developing areas leading to an influx of processed food products [28].

\subsection{Aim of this review}

This review summarises the physical and mental health consequences of obesity in women. It also compiles the mechanisms by which obesity may lead to these problems.

Due to space limitations, this book chapter does not assess the quality of the cited studies, nor does it intend to cover all the consequences of obesity. Therefore, the sequelae of obesity, which are equally present in men and women, are not a focus of this chapter.

\section{Physical health consequences of obesity in women}

\subsection{Cancer}

Obesity has been found to increase cancer risk and affect survival rates in both genders [29-31]. However, the increased risk of different types of cancer varies among men and women. The WHO states that breast, cervical, colorectal, lung and stomach cancer are leading in women's cancer statistics [32]. A systematic review and meta-analysis of prospective observational studies showed that an increase of BMI by $5 \mathrm{~kg} / \mathrm{m}^{2}$ was strongly associated with an elevated risk of endometrial, gallbladder, oesophageal, and kidney cancer in women. A weaker positive association was found between BMI and postmenopausal breast, pancreatic, thyroid and colon cancer [7]. In addition, obesity was found to increase mortality rates for breast, uterine, cervical and ovarian cancer in women [33]. The higher mortality rates may be a result of delayed screenings, obesity-associated comorbidities, poorer treatment effects, and increased surgical and radiotherapy complications in obese women [8].

\subsubsection{Mechanisms linking obesity and cancer}

Various mechanisms are suggested to link obesity with cancer. In the ATs of severely obese individuals, the inability of adipocytes to further expand may lead to inflammatory triggers, including hypoxia following cell death, free fatty acid release and a systematic inflammatory 
status [34, 35]. These inflammatory conditions may have tumour-promoting effects by inducing inflammatory cascades via the production of cytokines [36-38]. Additionally, local inflammatory processes in AT can directly contribute to cancer development. For example, a previous study examined signs of mammary tissue inflammation, including increased activity of macrophages in patients with early-stage breast cancer [5]. Inflammation and tumour growth may also be promoted via imbalance in the gut microbiome, the composition of which can be negatively influenced by a high-fat diet (HFD). Dysbiosis within the microbiome has been suggested to lead to elevated gut permeability $[39,40]$. In this process, bacterial components appear to activate immune receptors, including Toll-like receptor 4 , which contributes to the systemic inflammatory response in obesity [38].

Under premenopausal conditions, obese women may be better protected against inflammation originating from AT as they have a more favourable subcutaneous fat, rather than visceral fat storage [41, 42]. Visceral AT has repeatedly been demonstrated to be more systematically harmful [35, 43]. In addition, the female sex hormone, oestrogen, is considered to support an anti-inflammatory immune response [26] and to decrease the production of pro-inflammatory cytokines, including interleukin (IL)- 6 and tumour necrosis factor- $\alpha$ (TNF- $\alpha$ ), and thereby protect against carcinogenesis [44, 45]. However, there is an alteration in hormone status in women during menopause, with rapid hypoestrogenemia, relative hyperandrogenemia and a decrease in the hepatic production of sex-hormone binding globulin (SHBG), which increases the bioavailability of androgens [46]. This is accompanied by the accumulation of visceral fat independent of the increase in subcutaneous fat due to increasing age $[47,48]$. Therefore, women do not appear to be protected by the anti-inflammatory effects of oestrogen, which renders them more susceptible to post-menopausal metabolic complications and cancer [37, 49].

If the oestrogen levels of obese and non-obese postmenopausal women are compared, the oestrogen levels in obese postmenopausal women are higher than in their non-obese peers. This is explained by aromatase activity in AT, which catalyses the conversion of testosterone into estrogens [50,51]. In addition, aromatase activity is exponentiated by inflammatory mediators derived from AT, including prostaglandin E2, IL-6 and TNF- $\alpha[52,53]$. Despite the anti-inflammatory features of oestrogen, these relatively high oestrogen levels in obese postmenopausal women have been suggested to increase the risk of oestrogen-dependent breast cancer after menopause $[6,51,52,54]$.

The gut microbiome also appears to be capable of influencing oestrogen levels, possibly by enzymatic deconjugation, and thus contributing to cancer development [40]. However, the underlying mechanisms remain to be fully elucidated.

The metabolic comorbidities of obesity itself also increase cancer rates. An increased cancer rate in connection with DM II has been observed in liver, endometrial, pancreatic, colorectal, bladder, and breast cancer [55].

\subsubsection{Breast cancer}

Breast cancer is the leading type of cancer among women aged 20-59 years worldwide [56]. The obesity-related risk of developing breast cancer varies depending on menopausal and hormone 
receptor status $[6,40]$. The majority of studies have shown that obese women are at increased risk of oestrogen receptor (ER)-positive postmenopausal cancer [57]. ER-positive breast cancer is the most common subtype and accounts for $70 \%$ of all breast cancer cases [40,58].

Previous studies have found central adiposity to be an independent predictor of both postmenopausal and premenopausal breast cancer risk [59-61]. Obesity has been consistently shown to increase rates of breast cancer in ER-positive postmenopausal women by 30 to $50 \%$. Weight gain in young adults has also been found to be associated with an elevated risk of postmenopausal ER-positive breast cancer, whereas weight loss, bariatric surgery and PA are consistently associated with reduced risk [6, 62-64]. Correspondingly, biological markers associated with breast cancer, including oestrogen, SHBG, CRP and IL-6, have been found to decrease following weight loss and as a consequence of PA $[65,66]$. Conversely, the tumour growth rates of mice fed an HFD have been reported to increase compared with those in normally fed mice when inoculated with breast cancer cells [67].

Studies of breast cancer mortality and survival rates have noted that adiposity is associated with reduced survival rates and higher rates of recurrence, irrespective of menopausal status and after adjustment for stage and treatment [68-72]. Additionally, obese patients with breast cancer often receive suboptimal treatment in terms of the doses of chemotherapy [73] and treatment appears to be less effective in patients with a BMI $>30 \mathrm{~kg} / \mathrm{m}^{2}$ [74].

The use of menopausal and postmenopausal hormone therapy (MHT) to mitigate unwanted menopause-related symptoms has been reported to increase ER-positive breast cancer risk; these estrogens may accumulate in mammary AT [75].

\subsubsection{Cervical cancer}

Cervical cancer is the second leading cancer type in women and is linked to the sexually transmitted infection, human papillomavirus [56]. Studies investigating the connection between obesity and cervical cancer have been limited and inconsistent [29, 33]. A published meta-analysis of nine studies with 128, 233 participants found no association between overweight, but a weak association between obese individuals and the risk of cervical cancer [76]. However, investigations have repeatedly shown that obese women are more likely to miss screening examinations, possibly due to embarrassment and discomfort [77, 78]. This may partly explain the higher mortality rates of obese patients with cervical cancer [33]. According to the subtypes of cervical cancer, obesity appears to be involved in the development of cervical adenocarcinoma rather than squamous cell carcinoma [8, 79].

\subsubsection{Endometrial cancer}

Adiposity has been established as a factor closely related to endometrial cancer risk and mortality rates $[7,31,80,81]$. A prospective study recruiting 1.2 million women in the United Kingdom found that $\sim 50 \%$ of the cases of endometrial cancer were attributable to being overweight or obese, and it was reported that the risk of endometrial cancer increased linearly with increasing BMI [30]. It has been estimated that there is a 2- to 4-fold increased risk of endometrial cancer in overweight or obese women $[8,29,82]$. As a causal mechanism for the 
association between obesity and endometrial cancer, increased circulating oestrogen levels, insulin resistance and inflammatory processes in AT have been proposed [82, 83]. In particular, unopposed oestrogen-its application in the absence of progesterone-has been shown to lead to an increased cancer risk via inducing the mitotic activity of endometrial cells [84]. Therefore, in premenopausal cancer, progesterone deficiency, rather than an excess of oestrogen, may be responsible for the effect of obesity on cancer risk [30]. Hyperleptinemia occurring in obesity has been reported to be involved in ovarian steroidogenesis, and leptin treatment in mice decreases progesterone levels [85]. Additionally, obesity-associated PCOS (see Section 2.3.1.) with anovulation or oligoovulation has been discussed as a possible consequence of chronic exposure to unopposed oestrogen [8].

\subsubsection{Kidney cancer}

The risk of renal cell cancer in overweight and obese men and women, compared with those of a normal weight, appears to be 1.5- to 2.5-fold higher in study populations [29]. Kidney cancer has been reported to show a dose-response relationship with increasing BMI [86]. The increase in risk with increasing BMI appears to be higher in women than in men and independent of blood pressure [87-89]. The positive association with obesity is predominantly found in clear cell type kidney cancer, which is the dominant histological subtype [89]. In contrast to breast and endometrial cancer, the risk of developing kidney cancer appears to be decreased in the presence of oestrogen, as ER activity inhibits renal cell carcinoma growth [90]. Therefore, metabolic-, inflammatory- and adipokine-related features of obesity may mediate the higher risk of kidney cancer. Kidney cancer is often found in diabetic individuals with hyperinsulinemia and hyperglycaemia, which are considered to be carcinogenic factors by generating increasing levels of pro-inflammatory cytokines, reactive oxygen species and lipid peroxidation [91]. AT-derived hormones, including leptin and insulin-like growth factor-1, contribute to the direct effect of obesity on kidney cancer [92], and elevated leptin levels have been be demonstrated to cause renal fibrosis directly [93]. Obesity is also likely to lead to glomerulopathy by increasing blood flow, arterial pressure, activation of the reninangiotensin-aldosterone system and consequently glomerular hyperfiltration, which, in turn, leads to microalbuminuria and loss of renal function [94, 95].

\subsubsection{Gastrointestinal cancer}

As gastrointestinal cancer is among the leading cancer types in women, it is worth mentioning that obesity increases their risk of incidence according to several studies. Obesity appears to be associated with a 2- to 3-fold increase in risk for adenocarcinoma of the oesophagus [29]. A higher BMI often leads to gastro-oesophageal reflux, and it is hypothesised that an increased occurrence of reflux explains the association between obesity and oesophagal adenocarcinoma [96]. Reflux is provoked by visceral fat accumulation with increasing pressure inside the abdominal cavity [97]. Again, women are more prone to this type of cancer after the menopause due to their redistribution of fat owing to the hypoestrogenic condition [98]. Similarly, an approximately 2-fold elevated risk of gallbladder cancer in women, but not in men, has been consistently demonstrated in previous studies [29]. It has been suggested that obesity provokes the development of gallstones, inducing local inflammatory stimuli. Gallstones and gallbladder cancer 
share common risk factors, including female gender [99]. Obesity increases the risk of stomach cancer, a common type of cancer in women $[29,56]$. This appears to be especially true for gastric cardia rather than non-cardia gastric cancer [29, 100, 101], however, no gender differences have been found [101]. Colorectal Cancer (CRC) is the second most common type of cancer contributing to mortality rates in both men and women. Although obesity has been shown to be a more significant risk factor for colon cancer in men rather than women, there is a striking percentage of $18 \%$ by which an increase of $5 \mathrm{~kg} / \mathrm{m}^{2}$ in BMI can elevate the risk for colon cancer in both genders $[102,103]$. The linear association between BMI and CRC is stronger in premenopausal than postmenopausal women [102]. No differences in overall survival, survival by stage, or local or distant recurrence of CRC have been found between genders [104].

\subsection{Metabolic disorders}

\subsubsection{Metabolic syndrome (MS) and menopausal status}

According to the International Diabetes Federation, MS is characterised by a cluster of metabolic abnormalities, and increased blood pressure MS is associated with an increased risk of DM II, CVD and cerebrovascular disease (CeVD) [105]. Obesity and MS are significantly more prevalent in postmenopausal women, compared with men of the same age, and the increase in MS prevalence with age is more marked in women than in men $[2,40,106]$. In premenopausal women, PCOS appears to be a frequent clinical abnormality associated with MS [107].

Both endogenous and exogenous factors contribute to the association between weight gain during menopause and the occurrence of MS, including changing hormonal status accompanied by fat redistribution, physical inactivity, lower energy expenditure, unhealthy nutrition, medications (psychotropic drugs, insulin and steroids) and diseases [46, 108]. Unlike men, women have also been shown to develop MS as a response to work stress [2].

Possibly the most crucial link between MS and menopausal status is the essential role of oestrogen in the regulation of metabolic homeostasis. Under the influence of hormonal oestrogen, women are metabolically healthier than men; they exhibit higher insulin sensitivity, higher levels of high-density lipoprotein (HDL), and lower levels of triglyceride (TG) and low-density lipoprotein (LDL)-cholesterol, as well as beneficial subcutaneous fat distribution and inhibited lipogenesis by suppressed lipoprotein-lipase activity [108-111]. In contrast, rodent experiments show that, following menopause or ovariectomy, there is a marked decline in insulin sensitivity alongside an increase in fat mass, and elevations in circulating inflammatory markers, LDL, TG and fatty acids [108]. Unfortunately, aromatase-derived estrogens in obesity do not protect women from metabolic disturbances [46]. This is possibly due to the finding that ER-expression changes during menopause and alterations of ER in AT affect inflammatory processes and the distribution of fat regardless of circulating estrogens [112]. It has been suggested that only oestrogen levels in stable physiological concentrations are metabolically favourable, whereas supraphysiological levels or the overstimulation of ER may induce IR and DM II [108]. The relative surplus of androgens-from continued production in the adrenal gland-in conditions lacking estrogens may also contribute to the onset of MS, particularly regarding IR and the growth of visceral fat [113]. Gonadotropins, which are elevated following menopause in response to the peripheral drop of hormones, stimulate further androgen 
synthesis. Low levels of SHBG also appear to have a significant impact on the progress of IR, whereas hyperinsulinemia itself can boost ovarian androgen production [46].

There is evidence from animal experiments that, with the exception of sex hormones and gonads, different sex chromosome makeup may also contribute to differences in food intake, fat accumulation, fatty liver, hyperinsulinemia and hyperlipidemia between men and women [42]. However, in studies involving humans, physiological changes during the menopause appear to represent the most crucial gender-related factor for the increased prevalence of MS in women following the menopause in comparison to their age-matched male counterparts.

\subsubsection{Type II diabetes (DM II)}

Being overweight or obese is considered to be the main risk factor for developing DM II. A previous study found that, if a woman has a BMI of $\geq 25 \mathrm{~kg} / \mathrm{m}^{2}$, her relative risk of DM II is $\sim 5$, whereas the risk for a man is between 2 and 3 [114]. With MS as a predictor, it is not surprising that the prevalence of DM II in women after the menopause increases at a higher rate than that of men [115]. However, other conditions and diseases are more prevalent at this time in a women's life, including sleep disturbances and depression, which are independent risk factors for diabetes [113]. Substantial evidence highlights that the risk of the DM II depends on the onset of menopause; a natural menopause with an average onset age of $\sim 50$ years does not appear to affect the occurrence of DM II, whereas premature menopause, regardless of whether it is caused naturally or surgically by hysterectomy with bilateral oophorectomy, increases the risk of DM II [106]. In contrast, premenopausal women have a reduced incidence of DM II compared with age-matched men [108].

Large observational studies and a long-term randomised controlled trial examining the use of MHT in women with diabetes found an improved disease outcome, corroborating the oestrogen-deficiency theory in middle-aged women $[106,116]$. However, study results are conflicting $[117,118]$ and current knowledge is not sufficient to recommend the use of MHT in women with MS or diabetes, with CVD risk evaluation being advised prior to initiating MHT [106].

\subsection{Cardiovascular and cerebrovascular diseases}

Although evidence suggests that women have superior protection against CVD and experience CVD events on average 8 years later than men, CVD remains primary cause of death in women, accounting for $46 \%$ of deaths in older women worldwide [2, 56]. Protection against CVD is reversed in the presence of DM II, when the risk of CVD is almost doubled in men and more than three times higher in women [2]. Notably, the development of cardiac steatosis, a risk factor for heart failure, is more pronounced in the presence of impaired glucose tolerance (IGT) $[119,120]$. In CeVD in women, a prospective population-based study investigating 8419 participants aged $>55$ years showed that the cumulative incidence of CeVD was higher in women than in men [121]. Prospective studies and meta-analyses have found that both hyperglycaemia and hyperinsulinemia increase the risk of stroke, particularly in women [2, 122]. Additionally, the diagnosing of CeVD events appears to be delayed in women due to the less traditional stroke symptoms, including impaired consciousness and altered mental status [123]. 
In terms of cerebrovascular and cardiovascular health, oestrogen is described to enhance endothelial function and vasodilatory effects by increasing prostacyclin and nitric oxide levels, protecting the endothelium from TNF- $\alpha$-induced inflammation and downregulating levels of plasma LDL-cholesterol, and is considered to be neuroprotective [40, 46, 122, 124]. Accordingly, several studies have found that low-dose transdermal oestrogen application early following menopause was associated with attenuated risk of stroke [122].

\subsection{Osteoarthritis}

Osteoarthritis (OA) is a disease characterised by joint pain, stiffness and impaired movement. Menopausal women have an increased risk for OA. One study calculated the incidence rates of $\mathrm{OA}$ in men and women according to age for different joints and found incidence rates for knee, hip and hand arthritis higher in women [125, 126]. Prevalence rates of arthritis are related to body weight. A BMI increase by $5 \mathrm{~kg} / \mathrm{m}^{2}$ is associated with a $36 \%$ higher risk of OA. Systemic inflammation originating from the AT seems to be a crucial factor for the development of OA [127, 128].

\subsection{Reproductive health}

Obesity influences the onset of puberty as gonadal function is regulated by metabolic status. Insulin and leptin indirectly impinge hypothalamic neurons emitting gonadotropin-releasing hormone, a hierarchical hormone within the hypothalamic-pituitary-gonadal (HPG) axis [129, 130]. As the prevalence of childhood obesity has increased, a study found that the median age at menarche decreased by 3-5.5 months in the US between the late 1960s and 1990 [8].

In patients with PCOS, the age at menarche is ascertained to be $\sim 6$ months earlier than in unaffected girls, and premature pubarche is suggested to be the earliest manifestation of PCOS. As with premature pubarche, PCOS is often found in obese individuals, with only $20 \%$ of cases of PCOS in non-obese individuals [8]. Both obesity and PCOS are associated with irregularities in the menstrual cycle and disturbed metabolic features, including IR, increased leptin, and decreased adiponectin levels $[8,131]$. PCOS is clinically defined by the features hyperandrogenism, oligo- or anovulatory cycles and polycystic ovary [132]. Disturbed insulin sensitivity and hyperinsulinemia are widely believed to be the underlying causes of PCOS [133]. In particular, abdominal obesity combined with hyperinsulinemia is known to cause decreased SHBG levels and stimulate androgen production within the ovary, and possibly within the zona reticularis in the adrenal cortex [134-137]. Hyperleptinemia was found to be positively correlated with androgen levels in women with PCOS, and hyperleptinemic mice presented with prolonged menstrual cycles, atrophic ovary and reduced hypothalamic gonadotropin-releasing hormone at an older age [138, 139]. Leptin exerts its hypothalamic neuroregulatory function indirectly via interneuronal pathways, which can be attenuated by the leptin resistance typically found in response to hyperleptinemia in obese subjects [139-141]. Additionally, chronic elevation of circulating estrogens due to aromatisation in AT disturbs the HPG axis [142]. Taken together, obesity disrupts the ovulatory process via metabolic abnormalities affecting both peripheral and central hormonal derangements. 
A Nurses Health Study, which included 116,000 women, investigated ovulatory failure and menstrual cycle irregularity in women with and without PCOS, and reported an increased relative risk of infertility with increased BMI in all women [143]. Another study of 22,840 women reported reduced fecundity, even in obese women with regular cycles [8]. In obese women without PCOS, assisted reproduction is less successful and higher doses of gonadotropins are required for ovarian stimulation compared with woman of a normal weight [144].

Apart from the above-mentioned biological factors, social factors are also suggested to affect the reproductive condition of women. For example, a long-term study indicated that obese American women have lower fertility, partly due to a lower probability of marriage [145].

Contraception also appears to be negatively affected by obesity; studies have found a higher risk of contraception failure in heavier subjects when investigating different methods of contraception, including oral, transdermal and local hormonal contraception [8].

\subsection{Maternal health}

Being young was stated by the WHO to be one of the 10 highest health risks for women. This can partly be explained by the high number of deaths due to complications during pregnancy and childbirth, particularly in developing countries [3]. Obesity compromises maternal health by increasing the number of pregnancy-related ante-, peri- and postpartum complications. In addition, obesity holds potential for intergenerational programming, meaning that maternal obesity can increase the likelihood of weight gain with metabolic consequences and CVD risk in the adult life of the offspring [8, 143, 146]. In Europe and the US, 20-40\% of pregnant women are considered to be obese, due to the high prevalence of obesity, or they gain excessive weight during pregnancy [147]. In 2008, the prevalence of overweight and obesity in developing areas, including Africa, reached $40 \%$ in women of childbearing age [148].

Preconceptional obesity elevates the risk of gestational diabetes (GDM), gestational hypertension $(\mathrm{GH})$, preeclampsia (PE) and deep venous thromboembolism (DVT), all of which are related to higher maternal morbidity rates postpartum [8, 14, 143, 149]. A previous study assessed metabolic complications in relation to prepregnancy overweight and obesity (BMI $\left.\geq 30 \mathrm{~kg} / \mathrm{m}^{2}\right) 10$ years postpartum in premenopausal Chilean women. At 10 years post-delivery, women who were overweight and obese prior to pregnancy had significantly higher rates of IR, abdominal obesity and hypertriglyceridemia, compared with women of normal weight prepregnancy [150]. The risk of suffering from future DM II is higher for women with GDM than for those without. A metaanalysis revealed a 7-fold increased risk of DM II in women with GDM, compared with women without GDM [151]. A systematic literature review examined the incidence of DM II in women suffering from GDM and reported that the cumulative incidence increased steeply within 5 years of delivery and levelled off after 10 years [152]. Obese women were found to be $4.5-8.7$ times more likely to develop GH [153]. GH increases both maternal and foetal mortality with a 5- and 3-fold higher risk for PE and stillbirth, respectively [145]. PE, typically a late pregnancy or post-delivery syndrome characterised by new onset of hypertension and proteinuria, can often appear superimposed on established gestational or prior hypertension, and is frequently observed on a background of pre-existing maternal morbidities, including obesity [149]. Obese pregnant women are estimated to be at 3-10 times higher risk of PE [14]. PE increases the mortality rates of women 
during or shortly after pregnancy through severe complications, including eclampsia or HELLP syndrome, which is a life-threatening complication of pregnancy with haemolysis, elevated liver enzyme levels, and low platelet count. Excessive hypertension can also affect cerebral autoregulation and lead to permanent damage or death via cerebral haemorrhage [149]. During and after pregnancy, obesity increases the risk of DVT 4- to 5-fold [14].

Obesity is related to higher rates of miscarriage and preterm birth (PTB). A systematic review of the literature examining the association between BMI and PTB found an increase in the risk of PTB at different gestational ages in obese women, which was even higher for early PTB ( $<32$ weeks) in morbidly obese women (BMI $>40$ ) [154]. Additionally, obesity in women is associated with post-date delivery and a higher mean birth weight [155].

At the time of birth, obese women more often require assistance in delivery, for example induction of labour or c-section [8, 14]. Failure to progress with labour, administration of oxytocin, and epidural anaesthesia were more frequently experienced by obese women [155]. Emergency c-sections are more common among obese mothers due to macrosomia of the foetus which, in turn, results from IGT of the obese mother $[143,156]$. The odds ratio (OR) of c-section was increased from 1.43 to 2.36 when comparing morbidly obese and non-obese females [155]. Rates of postpartum haemorrhage, infection and venous thromboembolism are also elevated in obese women $[14,15,156]$.

\subsection{Neonatal health}

Newborns are also affected by morbid maternal obesity, with higher neonatal mortality rates owing to higher risk of neonatal complications, including hypoglycaemia, hyperbilirubinemia, birth injury, infections and respiratory distress syndrome [157, 158]. They are also more likely to suffer from malformations, including neural tube defects, spina bifida, cardiovascular anomalies, and cleft lip and palate. Intriguingly, the prevalence of gastroschisis in neonates was documented to be lower among obese mothers [8].

Even if obese mothers experience an uneventful pregnancy and delivery, the postpartum effects of obesity on the infant's and mother's lives often continue. Difficulties with breastfeeding are commonly observed between newborns and their obese mothers [14]. Among obese mothers, a lower prolactin response to suckling was observed leading to a delay of milk production and, thus, decreasing rates of breastfeeding initiation [159]. A recent investigation assessed intention and initiation of breastfeeding in different prepregnancy obesity classes according to BMI (normal: $18-24.9 \mathrm{~kg} / \mathrm{m}^{2}$, overweight: $25-29.9 \mathrm{~kg} / \mathrm{m}^{2}$, obese: $30-34.9 \mathrm{~kg} / \mathrm{m}^{2}$, very obese: $35-39.9 \mathrm{~kg} / \mathrm{m}^{2}$, and extremely obese: $\geq 40 \mathrm{~kg} / \mathrm{m}^{2}$ ). The authors noted that both intention and initiation were significantly lower among women with extreme obesity, while figures were similar and reduced only slightly reduced from normal to very obese women. In terms of intention to breastfeed, declared antepartum by study participants, extremely obese women were often younger, less well-educated, smokers and African American, compared with women in the other obesity classes suggesting that social and ethnic factors may play an additional role [160]. Similar figures and the inverse correlation between initiation of breastfeeding and higher classes of obesity were also confirmed in another study involving 8430 breastfeeding women [161]. In addition, the majority of studies observed a shortened duration and discontinuation of breastfeeding 


\begin{tabular}{|c|c|}
\hline Aspects of physical health affected by obesity & Specific consequences \\
\hline \multirow[t]{7}{*}{ Cancer } & ER-positive postmenopausal breast cancer \\
\hline & Endometrial cancer \\
\hline & Kidney cancer \\
\hline & Oesophageal adenocarcinoma \\
\hline & Gallbladder cancer \\
\hline & Gastric cardia cancer \\
\hline & Colorectal cancer \\
\hline \multirow[t]{2}{*}{ Metabolic disorders } & Metabolic syndrome \\
\hline & DM II \\
\hline \multirow[t]{2}{*}{ Vascular health } & CVD \\
\hline & CeVD \\
\hline \multirow[t]{3}{*}{ Reproductive health } & Premature pubarche \\
\hline & PCOS \\
\hline & Infertility \\
\hline Skeletal system & $\mathrm{OA}$ \\
\hline \multirow[t]{14}{*}{ Maternal health } & GDM \\
\hline & GH, PE, eclampsia \\
\hline & HELLP syndrome \\
\hline & DVT \\
\hline & Foetal macrosomia \\
\hline & Miscarriage, stillbirth \\
\hline & Maternal mortality $\uparrow$ \\
\hline & PTB, post-date delivery \\
\hline & Postpartum haemorrhage \\
\hline & Postpartum infection \\
\hline & Breastfeeding difficulties \\
\hline & More frequent need for: \\
\hline & - Induction of labour \\
\hline & - c-section \\
\hline \multirow[t]{7}{*}{ Neonatal health } & Frequent health consequences in newborns of obese mothers: \\
\hline & - Increased neonatal mortality \\
\hline & - Malformations \\
\hline & - Birth injury \\
\hline & - Hypoglycaemia \\
\hline & - Hyperbilirubinemia \\
\hline & - Respiratory distress syndrome \\
\hline
\end{tabular}

For details regarding the association between these physical health issues and obesity see Section 2 "Mental health consequences associated with obesity in women". Abbreviations: oestrogen receptor (ER), diabetes mellitus type II (DM II), cardiovascular disease (CVD), cerebrovascular disease (CeVD), polycystic ovary syndrome (PCOS), osteoarthritis (OA), gestational diabetes (GDM), gestational hypertension (GH), preeclampsia (PE), haemolysis, elevated liver enzymes and low platelet count (HELLP), deep venous thromboembolism (DVT), increase ( $\uparrow$ ), preterm birth (PTB), caesarean (c-) section.

Table 1. Physical health consequences of obesity in women. 
among obese women, even on adjustment for confounding factors [162]. Investigations assessing the maternal health consequences of breastfeeding found lower levels of fasting plasma glucose and insulin, as well as lower rates of diabetes and IGT in breastfeeding women [151].

As already mentioned, an unfavourably metabolic, intrauterine environment, for example promoted by an obese mother, can elevate the risk of developing obesity and related disorders in adulthood. For example, studies have shown that children of diabetic mothers had an almost 10 times greater risk of IGT at the age of 10-16 years, compared with controls, and the prevalence of obesity in children of diabetic mothers was higher than that in children whose mothers were non-diabetic, irrespective of maternal BMI. This intergenerational transition may contribute to the global epidemic of obesity [143]. Table 1 summarises the physical health consequences of obesity in women discussed in this section.

\section{Mental health consequences of obesity in women}

\subsection{Depression}

The gender difference in depression appears consistently in psychiatric epidemiology. A comprehensive review of general population studies revealed that major depression rates are more predominant in women than in men. Furthermore, depression seems to be more persistent in women, and female gender is a significant predictor of recurrence [18]. For depression, the female-to-male ratio was previously described as 1.5 [163]. Data from the general practice research database, which contains linked anonymised records of over 3 million patients registered in the UK, show that the incidence of depression in women is about twice as high as it is in men [164].

Irrespective of gender, obesity is regarded as an independent risk factor for depression and vice versa. A meta-analysis of studies examining the association between obesity and depression found an OR of $\sim 1.3-1.4$ for depression in obesity, and an OR of 1.7 for the inverse relationship [165]. Broadly, the association becomes more marked with increasing severity of obesity [8,165-167]. However, continued dieting is also seen as a risk factor for depression [166].

Different biological and psychosocial mechanisms are suggested to link obesity and depression, some of which are considered to be more distinctive in women. An upregulation of inflammatory mediators, including TNF- $\alpha$, has been shown repeatedly in obesity and depression, and may be a causal link between the two diseases. TNF- $\alpha$ has been found to activate indoleamine-2,3-dioxygenase, which degrades the serotonin precursor tryptophan leading to a central deficiency of serotonin [23, 24, 168]. Moreover, in both diseases, hormonal disturbances in the hypothalamic-pituitary-adrenal (HPA) axis are observed. Other hormones are also involved in the regulation of mood, appetite and the HPA axis, including leptin and ghrelin [166].

Particularly among women, who are considered to have a higher societal pressure to remain thin, obesity leads to poor self-image and self-esteem, as well as discrimination, which can promote 
the development of depression [8, 165, 166, 169]. Conversely, depression brings about poor food choices, overeating and reduced exercise due to a lack of motivation, which, in turn, contributes to the progression of obesity $[17,170,167]$.

It is often noted that a lack of PA is linked to depressive symptoms. Similarly, obese individuals show decreased PA, possibly due to limited function of their musculoskeletal system or sleep disturbances; this includes obstructive sleep apnoea syndrome (OSAS), which is accompanied by increased daytime sleepiness and elevated, pro-somnogenic cytokine levels [166, $171,172]$. However, a lack of physical activity may also be a causal factor contributing to the development of obesity.

As mentioned above, women across different age groups, ethnic backgrounds [20, 173-175], and specifically obese women $[115,176]$ are reported to be less physically active compared with their comparable male counterparts [28], which may lead to the development of depressive symptoms in addition to the burden of obesity [177].

Obesity in women may also be a consequence of psychiatric disorders. Women are $48 \%$ more likely than men to use any psychotropic medication following statistically controlling for demographics, health status, economic status and diagnosis [178]. In the US, data from the National Health and Nutrition Examination Surveys between 2005 and 2008 indicate that $11 \%$ of Americans aged $\geq 12$ years take antidepressant medication, with taking 2.5 times as many antidepressants as males. Women received more antidepressant medication across all age groups, which is not an expression of the severity of depression; when comparing the same degrees of depression between women and men, women were more likely to receive a prescription for antidepressants [179]. For psychopharmacological agents, including tri- and tetracyclic antidepressants and mood stabilisers, weight gain is known to be a frequent side effect; certain drugs are associated with weight gain of up to $20 \mathrm{~kg}$ [180].

Within the lives of women, they appear to be particularly prone to depression during pregnancy and menopausal transition [113,181]. At this life stage, the occurrence of obesity is simultaneously more likely. One review and meta-analysis involving 540,373 antenatal or postnatal women from countries worldwide, showed an increased OR of both antenatal (OR 1.43) and post-natal (OR 1.30) depression in obese women, compared with normal-weight women [153]. At the time of menopause, women often experience short-term changes in health and quality of life, involving sleep disturbance and affective symptoms, which are factors frequently causing women to seek medical attention [182]. Therefore, it is conceivable that women are prescribed more psychotropic drugs at this time, which may foster the progression of obesity in addition to the other factors mentioned above.

It has also been reported that oestrogen depletion can provoke depressive symptoms [40, 113].

\subsection{Anxiety disorders}

The male-to-female ratio for anxiety disorders is reported to be even higher than those for depression, ranging from 1.4 for any anxiety disorder to 1.7 for generalised anxiety, and up to 2.0 for panic disorder [163]. In terms of obesity, a recently published review reported inconsistent 
findings on the relationship between obesity and anxiety disorders. Although some studies have demonstrated poor correlation, others nave found clinically significantly associations of panic disorder, specific phobias and social anxiety with obesity in females $[165,183]$. The severity of obesity may influence these associations [183, 184].

In terms of the specific stages in women of pregnancy and menopause, another meta-analysis showed a higher risk for antenatal anxiety in obese women, compared with normal-weight women (OR 1.41), although there are few postnatal studies. The higher risk for antenatal anxiety has been explained by findings of qualitative research suggesting that women know of the elevated health risks associated with their obesity, which may increase their anxiety levels [153]. Only women with low, but not high, premenopausal anxiety levels have been shown to be more prone to developing anxiety during and after menopausal transition [185]. In relation to obesity, symptoms of anxiety were found to be associated with obesity neither pre- nor postmenopausally [184].

\subsection{Posttraumatic stress disorder}

The WHO estimated that $80 \%$ of the 50 million individuals experiencing trauma-related events, including violent conflicts and civil wars, are women and children, and the lifetime prevalence rates of violence against women vary between 16 and $50 \%$. At least one in five women is affected by rape or attempted rape in their lifetime. These figures of trauma prevalence among women are associated with correspondingly high rates of PTSD in women [18]. For PTSD, the femaleto-male ratio was 2.7, which was, alongside migraine, the highest ratio of all stress-related psychiatric disorders in a previous study [163]. Data from the Adult Psychiatric Morbidity Survey in England in 2014 showed the highest prevalence of PTSD in women aged 16-24 years, which was more than three times greater than in men [186]. There is evidence across several studies for an association between PTSD and obesity. A systematic review and meta-analysis of the available studies recorded an increased OR for obesity if individuals suffered from PTSD [187]. More severe symptoms, as well as early onset of PTSD, were found to be linked to a higher BMI, waist circumference, total cholesterol, leptin, CRP, blood pressure and reduced insulin sensitivity, indicating that PTSD is also associated with obesity-related diseases, including CVD and DM II [188]. Several mechanisms underlying how both diseases are linked to each other have been discussed in the literature. Various studies have found that PTSD and obesity are independently associated with higher rates of binge-eating, poor sleep, elevated inflammatory markers and altered levels of neuropeptides, shortened chromosome telomere length, mitochondrial dysfunction, increased endoplasmic reticulum stress and cortisol levels [189].

\subsection{Dementia}

Compared with men of the same age, the WHO considers older women to have lower pensions, a greater risk of poverty and poorer general health, including higher rates of dementia, combined with less access to health care and social services [3]. In particular, a low socioeconomic status appears to have a significant role in the development of dementia [190], and low socioeconomic status is also regarded as a risk factor for obesity [20]. 
Postmenopausal women show a decline in cognition, possibly due to the fall in oestrogen, which is considered to be neuroprotective [191] and associated with neuronal growth and certain aspects of memory [40].

Gender-specific prevalences of dementia differ along with the subtypes of dementia. While women exhibit an almost 2-fold increased risk of Alzheimer's disease (AD) compared with men, men are more susceptible to vascular dementia (VD), dementia with Lewi bodies and Parkinson's disease. However, AD contributes to the majority of cases of dementia. Risk factors for VD have been described to have a greater severity of impact on women. Gender also influences the disease course; women show a more rapid progression of AD than men once diagnosis is made [191]. In 2013, a population-based study in the UK found the prevalence of dementia to be highest in women aged $\geq 85$ years. At the age of $\geq 90$ years, $35 \%$ suffered from dementia. In this age group, the female brain appears to be more vulnerable to dementia, compared with in men [192]. As life expectancy increases, the number of women with dementia is growing steadily. Between 2012 and 2051, figures of dementia are anticipated to be doubled in women in the UK [193].

Dementia appears to be linked to weight in midlife. A study on twins, which included 8534 twins aged $\geq 65$ years examined the association between BMI and dementia. Dementia was diagnosed by performing the Mini Mental State Examination. BMI at midlife, considered to be $\sim 43$ years old, was assessed by self-reporting. Dementia was found in 350 of the 8534 participants. Compared with those without dementia, twins with dementia were older, had lower levels of education, lower current BMI, and were more likely to have diabetes, cardiovascular and cerebrovascular disease. However, there was a strong link between dementia and midlife BMI; even after adjustment for age, gender, education, diabetes, hypertension, stroke and heart disease, both overweight and obesity at midlife were associated with increased risk of dementia of different subtypes, compared with a normal BMI [194]. Another large population study obtained similar findings; participants who were obese at 30-39 years of age had a significantly increased risk of later dementia, although obesity at a later age did not appear to contribute significantly to the development of dementia [195]. However, a longitudinal study involving 392 adults without dementia aged 70 at baseline reported that being overweight at age 70 was a risk factor for $\mathrm{AD}$ in women [143] only.

Systemic inflammation may be an important link between obesity and dementia, as cytokines may provoke neuroinflammatory processes in the brain leading to neurodegeneration. There are hints in the literature that such inflammatory dysregulation in AD may be specifically relevant in females $[23,191,196]$. In women with diabetes, the risk of developing dementia was shown to be $19 \%$ greater than in men [191].

\subsection{Sleep disturbances}

Insomnia is defined by difficulty in initiating or maintaining sleep, waking up too early, or sleep that is chronically non-restorative or poor in quality. These symptoms have to be associated with some daytime impairment, for example fatigue or daytime sleepiness [197]. Insomnia impacts negatively on quality of life, workplace productivity, mental health and disease morbidity [198]. A meta-analysis on gender differences in insomnia noted a greater risk in women of suffering from insomnia, with an OR of 1.4. The trend of female predisposition was consistently found among all age groups, which was higher in the elderly [199]. Another meta-analysis documented 
a female-to-male ratio of 2.1 for insomnia [163]. Sleep disturbance is considered a hallmark of the menopausal transition, and insomnia affects $\sim 50 \%$ of middle-aged women. The postmenopausal risk of OSAS is indicated to be 3.5 times greater than in premenopausal women, independently of BMI [182].

In China, a study of 24,027 men and 33,677 women aged 30-79 years investigated the association between sleep duration and DM II. They found that short $(\leq 5 \mathrm{~h})$ and long sleep durations ( $\geq 10 \mathrm{~h}$ ) were significantly associated with DM II in postmenopausal women, but not in premenopausal women or men [200]. A similar result was reported by the National Health Service among women in the UK, with a U-shaped association between sleep duration and DM II. However, this relationship was attenuated following adjustment for BMI [113].

In addition to sleeping problems appearing to favour the development of obesity, obesity also give rise to sleep disturbances. Sleep restriction has been demonstrated to lead to higher food intake, poor food choices and unhealthy eating behaviour and, therefore, may encourage weight gain and obesity [201, 202]. Additionally, prolonged sleep duration (>8 h/night) was described as a risk factor for obesity although to a lesser extent [203]. Despite excessive sleepiness, it has been reported that up to $50 \%$ of adults with OSAS also suffer from insomnia [197]. Obesity is generally accepted as predisposing to OSAS, and $70 \%$ of patients with OSAS are obese. Weight loss significantly improves OSAS, and OSAS itself independently deteriorates the comorbidities of obesity by augmenting IR, glucose and TG levels, as well as markers of inflammation, arterial stiffness and atherosclerosis [204, 205]. In general, obesity is also associated with excessive daytime sleepiness (EDS), often due to OSAS but also found independently [206]. Hypercortisolemia and the increased production of somnogenic, pro-inflammatory cytokines have also been shown to be associated with obesity-related low sleep efficiency and EDS [207]. EDS in obesity may prevent individuals from being active during the day, therefore leading to weight gain. Moreover, individuals with EDS may tend towards daytime napping, altering nocturnal sleep [208]. This may lead to a vicious circle of impaired sleep, EDS, reduced PA and changing dietary patterns, resulting in further weight gain. Table 2 summarises the mental health issues in women with obesity.

\begin{tabular}{|c|c|}
\hline Aspects of mental health affected by obesity & Specific consequences \\
\hline Affective disorders & Depression \\
\hline \multirow[t]{4}{*}{ Anxiety disorders } & Panic disorder \\
\hline & Phobia \\
\hline & Social anxiety \\
\hline & PTSD \\
\hline \multirow[t]{2}{*}{ Neurodegenerative diseases } & $\mathrm{AD}$ \\
\hline & VD \\
\hline \multirow[t]{2}{*}{ Sleep disturbances } & OSAS \\
\hline & EDS \\
\hline $\begin{array}{l}\text { For details regarding the association betwee } \\
\text { consequences of obesity in women". Abbrevi } \\
\text { vascular dementia (VD), obstructive sleep apn }\end{array}$ & $\begin{array}{l}\text { health issues and obesity see Section } 3 \text { "Mental health } \\
\text { natic stress disorder (PTSD), Alzheimer dementia (AD), } \\
\text { OSAS), excessive daytime sleepiness (EDS). }\end{array}$ \\
\hline
\end{tabular}

Table 2. Mental health issues in women with obesity and the specific consequences. 


\section{Discussion}

\subsection{Summary of findings}

Obesity has an impact on the majority of the 10 top health issues affecting women. ER-positive cancer types, including postmenopausal breast and endometrial cancer, are highly associated with obesity as oestrogen levels rise with BMI. Other detrimental effects of excessive fat accumulation are known to be involved in elevated cancer risk and the development of other sequelae in women. Among these are a systematic inflammatory process, often combined with an imbalance in AT deriving cytokines, disturbances in metabolic homoeostasis, alteration in the composition of the gut microbiome, increased gastro-oesophageal reflux and the emergence of gallstones. Young, obese women encounter more difficulties during pregnancy, particularly in developing countries where gynaecological care is often inadequate. Obesity gives rise to reduced fecundity and is associated with PCOS. By contrast, older women are more likely to suffer from AD than male counterparts, with increased risk in the presence of obesity at midlife. The female-to-male ratio of obesity-related MS, frequently resulting in DM II, CDV and CeVD, becomes inverted following the menopause, with prevalence rates increasing more sharply in women than in men. In terms of mental health, women appear to be more negatively affected than men for almost every stress-related psychiatric disorder, with the exception of alcohol and drug abuse [163]. Correspondingly, women receive more psychopharmacological medication, often leading to weight gain. Table 3 summarises the mechanisms linking obesity with its associated comorbidities.

\subsection{Important aspects of obesity specific to women}

\subsubsection{Menopause}

The causes, consequences and associated disorders of obesity appear to differ among women and men due to specific gender-related factors. Physiological changes during the menopause leading to visceral fat storage may represent a crucial gender-related factor for the increased prevalence of obesity-associated comorbidities after the menopause. Consideration of the menopausal transition essential as life expectancy continues to increase. Between 2000 and 2025 , the number of women aged $\geq 50$ years old will increase by $60 \%$, and women are estimated to spend more than a third of their life beyond the menopausal transition [40, 209].

\subsubsection{Socioeconomic and cultural issues}

Socioeconomic status appears to affect men and women differently. Women with a poor background have higher rates of obesity and sequelae than men, whereas men with a higher socioeconomic status are more susceptible to MS than women. Work-stress was found to have a higher impact on the development of MS in women than men. In conservative societies, women are unable to perform PA in public and, in general, women appear to be less active than men. Commonly, women are under a higher societal pressure to remain thin, which may lead to women having a poorer self-image than men, followed by depressive symptoms and poor food choices. In addition, obese women are often reported to feel uncomfortable in 


\begin{tabular}{|c|c|}
\hline Area of concern & Specific factors linking obesity to health issues in women \\
\hline Socioeconomic factors & $\begin{array}{l}\text { Low socioeconomic status } \\
\text { Low educational level } \\
\text { Ideal of thinness } \\
\text { Cultural restrictions }\end{array}$ \\
\hline Psychosocial factors & $\begin{array}{l}\text { Probability of marriage } \downarrow \\
\text { Shame } \\
\text { Sleep disturbances } \\
\text { Quality of life } \downarrow \\
\text { Violence against women }\end{array}$ \\
\hline Behavioural factors & $\begin{array}{l}\text { Physical activity } \downarrow \\
\text { Unhealthy nutrition } \\
\text { Frequent dieting } \\
\text { Binge-eating } \\
\text { Avoidance of preventive medical screenings }\end{array}$ \\
\hline Factors associated with ageing & $\begin{array}{l}\text { Menopause } \\
\text { Changing hormonal status (oestrogen } \downarrow \text {, SHBG } \downarrow \text { ) } \\
\text { Fat redistribution }\end{array}$ \\
\hline Microbiome & $\begin{array}{l}\text { Dysbiosis of microbiome } \\
\text { TLR } 4 \text { activation }\end{array}$ \\
\hline Gastrointestinal system & $\begin{array}{l}\text { Intraabdominal pressure } \uparrow \\
\text { Gastro-oesophageal reflux } \\
\text { Gallstones }\end{array}$ \\
\hline Vascular system & $\begin{array}{l}\mathrm{RR} \uparrow \\
\text { Atherosclerosis }\end{array}$ \\
\hline Intracellular pathophysiology & $\begin{array}{l}\text { Reactive oxygen species } \uparrow \\
\text { Endoplasmic reticulum stress } \uparrow \\
\text { Mitochondrial dysfunction }\end{array}$ \\
\hline Metabolism & $\begin{array}{l}\text { Glucose } \uparrow, \text { IGT } \\
\text { Triglycerides } \uparrow\end{array}$ \\
\hline Hormones & $\begin{array}{l}\text { Oestrogen } \uparrow \\
\text { Insulin } \uparrow \text {, insulin sensitivity } \downarrow \\
\text { Cortisol } \uparrow \\
\text { IGF- } 1 \uparrow \\
\text { Changes in neuropeptides }\end{array}$ \\
\hline Adipocytokines & $\begin{array}{l}\text { Adiponectin } \downarrow \\
\text { Leptin } \uparrow \\
\text { IL-6 } \uparrow \\
\text { TNF- } \alpha \uparrow\end{array}$ \\
\hline Problems associated with medical measures & $\begin{array}{l}\text { Treatment effects } \downarrow \\
\text { Complications of surgery and radiation } \uparrow \\
\text { Inappropriate prescription of medication } \\
\text { Medication-induced weight gain } \\
\text { MHT }\end{array}$ \\
\hline
\end{tabular}

For details see text. Abbreviations: increase $(\uparrow)$, decrease $(\downarrow)$, sex-hormone binding globulin (SHBG), Toll-like receptor 4 (TLR4), blood pressure (RR), interleukin (IL)-6, tumour necrosis factor-alpha (TNF- $\alpha$ ), impaired glucose tolerance (IGT), postmenopausal hormone therapy (MHT).

Table 3. Mechanisms linking obesity to associated physical and mental health issues in women. 
gynaecological screenings and tend to avoid these, which may result in higher mortality rates for cervical cancer in obese women.

\subsection{Obesity and its consequences: the problem of causality}

The direction of causality is often unclear. Obesity can be the cause of associated diseases and issues, however it can also be a sequelae of another disorder. Moreover, obesity and associated comorbidities may share causal factors. For example, obesity can lead to an increase in pro-inflammatory cytokine production, which is a risk factor for depression; depression, in turn, can lead to decreased PA and to the intake of weight-inducing psychopharmacological agents, finally contributing to the development of obesity. Additionally, sleep disturbances with consecutive EDS may be a causal factor for the development of obesity and depression. Therefore, it appears to be more appropriate to discuss "associated disorders" or "comorbidities", rather than "consequences" of obesity as, in many cases, the chain of causality is not well established.

Similarly, the mechanisms linking obesity to its associated diseases and problems are not specific. For example, an increase in pro-inflammatory cytokine production in the AT can contribute to the development of cancer, and metabolic and vascular disorders, and can be a risk factor for depression, dementia and sleep disturbances.

Obesity itself is a disorder of multifactorial causes. In addition, its consequences are linked to obesity by several factors at different levels, including socioeconomic, psychosocial and behavioural factors, and factors associated with ageing, microbiome-related mechanisms, the gastrointestinal and the vascular system, intracellular pathophysiology, problems with metabolism, hormones, adipocytokines and problems associated with medical measures, as shown in Table 3.

\subsection{Limitations}

This review does not assess the quality of the cited studies nor weigh the importance of the various consequences against one another due to space restrictions. Therefore, this chapter provides a list of the sequelae of obesity important for women with a superficial explanation of the underlying mechanisms. Moreover, the chapter does not cover the consequences of obesity, which are equally present in men and women. Therefore, the important general health problems associated with obesity concerning the eyes, respiratory system, kidneys, skeleton and muscles have not been discussed.

\section{Conclusion}

To conclude, this chapter identifies the risk factors leading to obesity, which are more prevalent in women than in men. These factors include a lack of PA in sport and leisure, psychiatric 
problems of depression, PTSD, sleep problems and EDS, and the fact that women receive more psychopharmacological medication, compared with men.

Cancer, reproductive and maternal impairment, MS, depression and dementia are consequences of obesity with a high prevalence in women. Therefore, treatment should incorporate gender-related strategies to appropriately combat obesity and its sequelae in women. For example, clinicians may encourage particularly obese women to participate in gynaecological screenings, even if they are reluctant for their bodies be exposed owing to poor self-image.

However, despite decades of prominent research, including large-scale and molecular studies, the prevalence of obesity and its physical and mental consequences is increasing. Obesity and its sequelae are the result of a complex network of mutual interactions, including social, cultural, psychological and biological factors. This consideration indicates that there is no easy solution for such complex problems.

\section{Acknowledgements}

The authors would like to thank all colleagues at the Max-Planck-Institute of Psychiatry in Munich, the University Hospital Leipzig and King's College London, who were involved in fruitful and helpful discussions concerning obesity and its consequences.

\section{Conflict of interest}

The authors declare that there is no conflict of interest.

\section{Author details}

Julia Weschenfelder, Jessica Bentley and Hubertus Himmerich*

*Address all correspondence to: hubertus.himmerich@kcl.ac.uk

Department of Psychological Medicine, King's College London, London, UK

\section{References}

[1] WHO. Obesity and Overweight - Fact Sheet. 2017. Available from: http://www.who.int/ mediacentre/factsheets/fs311/en/ [Accessed: 25 Jul 2017]

[2] Pucci G, Alcidi R, Tap L, et al. Sex- and gender-related prevalence, cardiovascular risk and therapeutic approach in metabolic syndrome: A review of the literature. Pharmacological Research. Jun 2017;120:34-42. DOI: 10.1016/j.phrs.2017.03.008 
[3] WHO. Ten Top Issues for Women's Health. 2017. Available from: http://www.who.int/ life-course/news/commentaries/2015-intl-womens-day/en/ [Accessed: 2 Aug 2017]

[4] Chen WY. Exogenous and endogenous hormones and breast cancer. Best Practice \& Research. Clinical Endocrinology \& Metabolism. Aug 2008;22:573-585. DOI: 10.1016/j. beem.2008.08.001

[5] Vaysse C, Lomo J, Garred O, et al. Inflammation of mammary adipose tissue occurs in overweight and obese patients exhibiting early-stage breast cancer. NPJ Breast Cancer. 2017;3:19. DOI: 10.1038/s41523-017-0015-9

[6] Picon-Ruiz M, Morata-Tarifa C, Valle-Goffin JJ, et al. Obesity and adverse breast cancer risk and outcome: Mechanistic insights and strategies for intervention. CA: A Cancer Journal for Clinicians. Sep 2017;67:378-397. DOI: 10.3322/caac.21405

[7] Renehan AG, Tyson M, Egger M, et al. Body-mass index and incidence of cancer: A systematic review and meta-analysis of prospective observational studies. Lancet. 16 Feb 2008;371:569-578. DOI: 10.1016/s0140-6736(08)60269-x

[8] Kulie T, Slattengren A, Redmer J, et al. Obesity and women's health: An evidence-based review. Journal of American Board of Family Medicine. Jan-Feb 2011;24:75-85. DOI: 10.3122/jabfm.2011.01.100076

[9] Lash MM, Armstrong A. Impact of obesity on women's health. Fertility and Sterility. May 2009;91:1712-1716. DOI: 10.1016/j.fertnstert.2008.02.141

[10] Delitala AP, Capobianco G, Delitala G, et al. Polycystic ovary syndrome, adipose tissue and metabolic syndrome. Archives of Gynecology and Obstetrics. 22 Jun 2017. DOI: 10.1007/ s00404-017-4429-2

[11] Lindsay KL, Brennan L, Rath A, et al. Gestational weight gain in obese pregnancy: Impact on maternal and foetal metabolic parameters and birthweight. Journal of Obstetrics and Gynaecology. Jan 2018;38:60-65. DOI: 10.1080/01443615.2017.1328670

[12] White SL, Pasupathy D, Sattar N, et al. Metabolic profiling of gestational diabetes in obese women during pregnancy. Diabetologia. Oct 2017;60:1903-1912. DOI: 10.1007/ s00125-017-4380-6

[13] Canto-Cetina T, Coral-Vazquez RM, Rojano-Mejia D, et al. Higher prepregnancy body mass index is a risk factor for developing preeclampsia in Maya-mestizo women: A cohort study. Ethnicity \& Health. 6 Apr 2017:1-9. DOI: 10.1080/13557858.2017.1315367

[14] Poston L, Caleyachetty R, Cnattingius S, et al. Preconceptional and maternal obesity: Epidemiology and health consequences. The Lancet Diabetes and Endocrinology. Dec 2016;4:1025-1036. DOI: 10.1016/s2213-8587(16)30217-0

[15] Harper A. Reducing morbidity and mortality among pregnant obese. Best Practice \& Research. Clinical Obstetrics \& Gynaecology. Apr 2015;29:427-437. DOI: 10.1016/j. bpobgyn.2014.08.010 
[16] Boots C, Stephenson MD. Does obesity increase the risk of miscarriage in spontaneous conception: A systematic review. Seminars in Reproductive Medicine. Nov 2011;29:507513. DOI: 10.1055/s-0031-1293204

[17] Luppino FS, de Wit LM, Bouvy PF, et al. Overweight, obesity, and depression: A systematic review and meta-analysis of longitudinal studies. Archives of General Psychiatry. Mar 2010;67:220-229. DOI: 10.1001/archgenpsychiatry.2010.2

[18] WHO. Gender Disparities and Mental Health. 2017. Available from: http://www.who. int/mental_health/prevention/genderwomen/en/ [Accessed: 4 Sep 2017]

[19] Piontak JR, Russell MA, Danese A, et al. Violence exposure and adolescents' same-day obesogenic behaviors: New findings and a replication. Social Science \& Medicine. Sep 2017;189:145-151. DOI: 10.1016/j.socscimed.2017.07.004

[20] Tate NH, Dillaway HE, Yarandi HN, et al. An examination of eating behaviors, physical activity, and obesity in african american adolescents: Gender, socioeconomic status, and residential status differences. Journal of Pediatric Health Care. May-Jun 2015;29:243254. DOI: 10.1016/j.pedhc.2014.11.005

[21] Trayhurn P, Wood IS. Signalling role of adipose tissue: Adipokines and inflammation in obesity. Biochemical Society Transactions. Nov 2005;33:1078-1081. DOI: 10.1042/bst2005 1078

[22] Golia E, Limongelli G, Natale F, et al. Inflammation and cardiovascular disease: From pathogenesis to therapeutic target. Current Atherosclerosis Reports. Sep 2014;16:435. DOI: $10.1007 / \mathrm{s} 11883-014-0435-\mathrm{Z}$

[23] Himmerich H, Berthold-Losleben M, Pollmacher T. The relevance of the TNF-alpha system in psychiatric disorders. Fortschritte der Neurologie-Psychiatrie. Jun 2009;77:334345. DOI: $10.1055 / \mathrm{s}-0028-1109420$

[24] Schmidt FM, Weschenfelder J, Sander C, et al. Inflammatory cytokines in general and central obesity and modulating effects of physical activity. PLoS One. 2015;10:e0121971. DOI: 10.1371/journal.pone.0121971

[25] Combs TP, Berg AH, Rajala MW, et al. Sexual differentiation, pregnancy, calorie restriction, and aging affect the adipocyte-specific secretory protein adiponectin. Diabetes. Feb 2003;52:268-276

[26] Agrawal M, Kern PA, Nikolajczyk BS. The immune system in obesity: Developing paradigms amidst inconvenient truths. Current Diabetes Reports. 15 Aug 2017;17:87. DOI: 10.1007/s11892-017-0917-9

[27] Lynes MD, Tseng YH. Deciphering adipose tissue heterogeneity. Annals of the New York Academy of Sciences. Jan 2018;1411:5-20. DOI: 10.1111/nyas.13398

[28] Kanter R, Caballero B. Global gender disparities in obesity: A review. Advances in Nutrition. Jul 2012;3:491-498. DOI: 10.3945/an.112.002063

[29] Calle EE, Thun MJ. Obesity and cancer. Oncogene. Aug 2004;23(23):6365-6378. DOI: 10.1038/sj.onc. 1207751 
[30] Reeves GK, Pirie K, Beral V, et al. Cancer incidence and mortality in relation to body mass index in the million women study: Cohort study. British Medical Journal. Dec 2007;335:1134. DOI: 10.1136/bmj.39367.495995.AE

[31] Renehan AG, Soerjomataram I. Obesity as an avoidable cause of cancer (attributable risks). Recent Results in Cancer Research. 2016;208:243-256. DOI: 10.1007/978-3-319-42542-9_13

[32] WHO. Cancer Facts. 2017. Available from: http://www.who.int/cancer/en/ [Accessed: 9 Oct 2017]

[33] Calle EE, Rodriguez C, Walker-Thurmond K, et al. Overweight, obesity, and mortality from cancer in a prospectively studied cohort of U.S. adults. The New England Journal of Medicine. 24 Apr 2003;348:1625-1638. DOI: 10.1056/NEJMoa021423

[34] Gregor MF, Hotamisligil GS. Inflammatory mechanisms in obesity. Annual Review of Immunology. 2011;29:415-445. DOI: 10.1146/annurev-immunol-031210-101322

[35] Tchernof A, Despres JP. Pathophysiology of human visceral obesity: An update. Physiological Reviews. Jan 2013;93:359-404. DOI: 10.1152/physrev.00033.2011

[36] Mantovani A, Allavena P, Sica A, et al. Cancer-related inflammation. Nature. 24 Jul 2008; 454:436-444. DOI: 10.1038/nature07205

[37] Himbert C, Delphan M, Scherer D, et al. Signals from the adipose microenvironment and the obesity-cancer link-a systematic review. Cancer Prevention Research (Philadelphia, PA). Sep 2017;10:494-506. DOI: 10.1158/1940-6207.capr-16-0322

[38] Iyengar NM, Gucalp A, Dannenberg AJ, et al. Obesity and cancer mechanisms: Tumor microenvironment and inflammation. Journal of Clinical Oncology. 10 Dec 2016;34:42704276. DOI: 10.1200/jco.2016.67.4283

[39] Torres-Fuentes C, Schellekens H, Dinan TG, et al. The microbiota-gut-brain axis in obesity. Lancet Gastroenterology \& Hepatology. Oct 2017;2:747-756. DOI: 10.1016/s24681253(17)30147-4

[40] Baker JM, Al-Nakkash L, Herbst-Kralovetz MM. Estrogen-gut microbiome axis: Physiological and clinical implications. Maturitas. Sep 2017;103:45-53. DOI: 10.1016/j. maturitas.2017.06.025

[41] Lemieux S, Prud'homme D, Bouchard C, et al. Sex differences in the relation of visceral adipose tissue accumulation to total body fatness. The American Journal of Clinical Nutrition. Oct 1993;58:463-467

[42] Reue K. Sex differences in obesity: X chromosome dosage as a risk factor for increased food intake, adiposity and co-morbidities. Physiology \& Behavior. 1 Jul 2017;176:174182. DOI: $10.1016 /$ j.physbeh.2017.02.040

[43] Meza-Perez S, Randall TD. Immunological functions of the Omentum. Trends in Immunology. Jul 2017;38:526-536. DOI: 10.1016/j.it.2017.03.002

[44] Naugler WE, Sakurai T, Kim S, et al. Gender disparity in liver cancer due to sex differences in MyD88-dependent IL-6 production. Science. 6 Jul 2007;317:121-124. DOI: 10.1126/science. 1140485 
[45] Kramer PR, Kramer SF, Guan G. 17 beta-estradiol regulates cytokine release through modulation of CD16 expression in monocytes and monocyte-derived macrophages. Arthritis and Rheumatism. Jun 2004;50:1967-1975. DOI: 10.1002/art.20309

[46] Kozakowski J, Gietka-Czernel M, Leszczynska D, et al. Obesity in menopause - Our negligence or an unfortunate inevitability? Przegląd Menopauzalny. Jun 2017;16:61-65. DOI: $10.5114 / \mathrm{pm} .2017 .68594$

[47] Lovejoy JC, Champagne CM, de Jonge L, et al. Increased visceral fat and decreased energy expenditure during the menopausal transition. International Journal of Obesity. Jun 2008;32:949-958. DOI: 10.1038/ijo.2008.25

[48] Donato GB, Fuchs SC, Oppermann K, et al. Association between menopause status and central adiposity measured at different cutoffs of waist circumference and waist-to-hip ratio. Menopause. Mar-Apr 2006;13:280-285. DOI: 10.1097/01.gme.0000177907.32634.ae

[49] Pfeilschifter J, Koditz R, Pfohl M, et al. Changes in proinflammatory cytokine activity after menopause. Endocrine Reviews. Feb 2002;23:90-119. DOI: 10.1210/edrv.23.1.0456

[50] Vihma V, Naukkarinen J, Turpeinen U, et al. Metabolism of sex steroids is influenced by acquired adiposity-a study of young adult male monozygotic twin pairs. The Journal of Steroid Biochemistry and Molecular Biology. Sep 2017;172:98-105. DOI: 10.1016/j. jsbmb.2017.06.007

[51] Engin A. Obesity-associated breast cancer: Analysis of risk factors. Advances in Experimental Medicine and Biology.2017;960:571-606.DOI:10.1007/978-3-319-48382-5_25

[52] Zahid H, Simpson ER, Brown KA. Inflammation, dysregulated metabolism and aromatase in obesity and breast cancer. Current Opinion in Pharmacology. Dec 2016;31:90-96. DOI: 10.1016/j.coph.2016.11.003

[53] Purohit A, Reed MJ. Regulation of estrogen synthesis in postmenopausal women. Steroids. Nov 2002;67:979-983

[54] Au CC, Furness JB, Brown KA. Ghrelin and breast cancer: Emerging roles in obesity, estrogen regulation, and cancer. Frontiers in Oncology. 2016;6:265. DOI: 10.3389/ fonc. 2016.00265

[55] Noto H. Unfolding link between diabetes and cancer. Journal of Diabetes Investigation. Aug 2017. DOI: 10.1111/jdi.12725

[56] WHO Fact Sheet Women. 2013. Available from: http://www.who.int/mediacentre/factsheets/fs334/en/ [Accessed: 18 Sep 2017]

[57] Calle EE, Kaaks R. Overweight, obesity and cancer: Epidemiological evidence and proposed mechanisms. Nature Reviews. Cancer. Aug 2004;4:579-591. DOI: 10.1038/nrc1408

[58] Kohler BA, Sherman RL, Howlader N, et al. Annual report to the Nation on the Status of Cancer, 1975-2011, featuring incidence of breast cancer subtypes by race/ethnicity, poverty, and state. Journal of the National Cancer Institute. Jun 2015;107:djv048. DOI: 10.1093/jnci/djv048 
[59] White AJ, Nichols HB, Bradshaw PT, et al. Overall and central adiposity and breast cancer risk in the sister study. Cancer. 15 Oct 2015;121:3700-3708. DOI: 10.1002/cncr.29552

[60] Suzuki Y, Tsunoda H, Kimura T, et al. BMI change and abdominal circumference are risk factors for breast cancer, even in Asian women. Breast Cancer Research and Treatment. Dec 2017;166:919-925. DOI: 10.1007/s10549-017-4481-4

[61] Nagrani R, Mhatre S, Rajaraman P, et al. Central obesity increases risk of breast cancer irrespective of menopausal and hormonal receptor status in women of south Asian ethnicity. European Journal of Cancer. Oct 2016;66:153-161. DOI: 10.1016/j.ejca.2016.07.022

[62] Parker ED, Folsom AR. Intentional weight loss and incidence of obesity-related cancers: The Iowa Women's health study. International Journal of Obesity and Related Metabolic Disorders. Dec 2003;27:1447-1452. DOI: 10.1038/sj.ijo.0802437

[63] Winder AA, Kularatna M, MacCormick AD. Does bariatric surgery affect the incidence of breast cancer development? A systematic review. Obesity Surgery. Nov 2017;27:3014-3020. DOI: 10.1007/s11695-017-2901-5

[64] Phipps AI, Chlebowski RT, Prentice R, et al. Body size, physical activity, and risk of triple-negative and estrogen receptor-positive breast cancer. Cancer Epidemiology, Biomarkers \& Prevention. Mar 2011;20:454-463. DOI: 10.1158/1055-9965.epi-10-0974

[65] van Gemert WA, Monninkhof EM, May AM, et al. Association between changes in fat distribution and biomarkers for breast cancer. Endocrine-Related Cancer. Jun 2017;24:297305. DOI: 10.1530/erc-16-0490

[66] Campbell KL, Foster-Schubert KE, Alfano CM, et al. Reduced-calorie dietary weight loss, exercise, and sex hormones in postmenopausal women: Randomized controlled trial. Journal of Clinical Oncology. 1 Jul 2012;30:2314-2326. DOI: 10.1200/jco.2011.37.9792

[67] Sabnis G, Schayowitz A, Goloubeva O, et al. Trastuzumab reverses letrozole resistance and amplifies the sensitivity of breast cancer cells to estrogen. Cancer Research. $15 \mathrm{Feb}$ 2009;69:1416-1428. DOI: 10.1158/0008-5472.can-08-0857

[68] Maliniak ML, Patel AV, McCullough ML, et al. Obesity, physical activity, and breast cancer survival among older breast cancer survivors in the cancer prevention study-II nutrition cohort. Breast Cancer Research and Treatment. Jan 2018;167:133-145. DOI: 10.1007/ s10549-017-4470-7

[69] Chan DS, Vieira AR, Aune D, et al. Body mass index and survival in women with breast cancer-systematic literature review and meta-analysis of 82 follow-up studies. Annals of Oncology. Oct 2014;25:1901-1914. DOI: 10.1093/annonc/mdu042

[70] Loi S, Milne RL, Friedlander ML, et al. Obesity and outcomes in premenopausal and postmenopausal breast cancer. Cancer Epidemiology, Biomarkers \& Prevention. Jul 2005;14: 1686-1691. DOI: 10.1158/1055-9965.epi-05-0042

[71] Copson ER, Cutress RI, Maishman T, et al. Obesity and the outcome of young breast cancer patients in the UK: The POSH study. Annals of Oncology. Jan 2015;26:101-112. DOI: 10.1093/annonc/mdu509 
[72] Rosenberg L, Czene K, Hall P. Obesity and poor breast cancer prognosis: An illusion because of hormone replacement therapy? British Journal of Cancer. 5 May 2009;100:14861491. DOI: $10.1038 /$ sj.bjc.6605025

[73] Griggs JJ, Mangu PB, Anderson H, et al. Appropriate chemotherapy dosing for obese adult patients with cancer: American Society of Clinical Oncology clinical practice guideline. Journal of Clinical Oncology. 1 May 2012;30:1553-1561. DOI: 10.1200/jco.2011.39.9436

[74] Ewertz M, Jensen MB, Gunnarsdottir KA, et al. Effect of obesity on prognosis after earlystage breast cancer. Journal of Clinical Oncology. 1 Jan 2011;29:25-31. DOI: 10.1200/ jco.2010.29.7614

[75] Stanczyk FZ, Mathews BW, Relationships SME. Of sex steroid hormone levels in benign and cancerous breast tissue and blood: A critical appraisal of current science. Steroids. Jul 2015;99:91-102. DOI: 10.1016/j.steroids.2014.12.011

[76] Poorolajal J, Jenabi E. The association between BMI and cervical cancer risk: A metaanalysis. European Journal of Cancer Prevention. May 2016;25:232-238. DOI: 10.1097/cej. 0000000000000164

[77] Gu W, Chen C, Zhao KN. Obesity-associated endometrial and cervical cancers. Frontiers in Bioscience (Elite Ed). 1 Jan 2013;5:109-118

[78] Maruthur NM, Bolen SD, Brancati FL, et al. The association of obesity and cervical cancer screening: A systematic review and meta-analysis. Obesity (Silver Spring). Feb 2009;17: 375-381. DOI: 10.1038/oby.2008.480

[79] Ursin G, Pike MC, Preston-Martin S, et al. Sexual, reproductive, and other risk factors for adenocarcinoma of the cervix: Results from a population-based case-control study (California, United States). Cancer Causes \& Control. May 1996;7:391-401

[80] Secord AA, Hasselblad V, Von Gruenigen VE, et al. Body mass index and mortality in endometrial cancer: A systematic review and meta-analysis. Gynecologic Oncology. Jan 2016;140:184-190. DOI: 10.1016/j.ygyno.2015.10.020

[81] De Ridder J, Julian-Almarcegui C, Mullee A, et al. Comparison of anthropometric measurements of adiposity in relation to cancer risk: A systematic review of prospective studies. Cancer Causes \& Control. Mar 2016;27:291-300. DOI: 10.1007/s10552-015-0709-y

[82] Shaw E, Farris M, McNeil J, et al. Obesity and endometrial cancer. Recent Results in Cancer Research. 2016;208:107-136. DOI: 10.1007/978-3-319-42542-9_7

[83] Plaza-Parrochia F, Romero C, Valladares L, et al. Endometrium and steroids, a pathologic overview. Steroids. Oct 2017;126:85-91. DOI: 10.1016/j.steroids.2017.08.007

[84] Key TJ, Pike MC. The dose-effect relationship between 'unopposed' oestrogens and endometrial mitotic rate: Its central role in explaining and predicting endometrial cancer risk. British Journal of Cancer. Feb 1988;57:205-212

[85] Ding X, Kou X, Zhang Y, et al. Leptin siRNA promotes ovarian granulosa cell apoptosis and affects steroidogenesis by increasing NPY2 receptor expression. Gene. 30 Oct 2017;633:28-34. DOI: 10.1016/j.gene.2017.08.028 
[86] Wang F, Xu Y. Body mass index and risk of renal cell cancer: A dose-response meta-analysis of published cohort studies. International Journal of Cancer. 1 Oct 2014;135:16731686. DOI: $10.1002 / \mathrm{ijc} .28813$

[87] Sanfilippo KM, McTigue KM, Fidler CJ, et al. Hypertension and obesity and the risk of kidney cancer in 2 large cohorts of US men and women. Hypertension. May 2014;63:934941. DOI: 10.1161/hypertensionaha.113.02953

[88] Wang Y, Chen X, Song Y, et al. Association between obesity and kidney disease: A systematic review and meta-analysis. Kidney International. Jan 2008;73:19-33. DOI: 10.1038/ sj.ki.5002586

[89] Wilson KM, Cho E. Obesity and kidney cancer. Recent Results in Cancer Research. 2016;208:81-93. DOI: 10.1007/978-3-319-42542-9_5

[90] Chen KC, Lin CM, Huang CJ, et al. Dual roles of 17-beta estradiol in estrogen receptordependent growth inhibition in renal cell carcinoma. Cancer Genomics \& Proteomics. May-Jun 2016;13:219-230

[91] Labochka D, Moszczuk B, Kukwa W, et al. Mechanisms through which diabetes mellitus influences renal cell carcinoma development and treatment: A review of the literature. International Journal of Molecular Medicine. Dec 2016;38:1887-1894. DOI: 10.3892/ ijmm.2016.2776

[92] Kovesdy CP, Furth SL, Zoccali C. Obesity and kidney disease: Hidden consequences of the epidemic. Future Science OA. Aug 2017;3:Fso159. DOI: 10.4155/fsoa-2016-0081

[93] Alix PM, Guebre-Egziabher F, Soulage CO. Leptin as an uremic toxin: Deleterious role of leptin in chronic kidney disease. Biochimie. Oct 2014;105:12-21. DOI: 10.1016/j.biochi. 2014.06.024

[94] de Jong PE, Verhave JC, Pinto-Sietsma SJ, et al. Obesity and target organ damage: The kidney. International Journal of Obesity and Related Metabolic Disorders. Dec 2002;26 (Suppl 4):S21-S24. DOI: 10.1038/sj.ijo.0802213

[95] Henegar JR, Bigler SA, Henegar LK, et al. Functional and structural changes in the kidney in the early stages of obesity. Journal of the American Society of Nephrology. Jun 2001;12:1211-1217

[96] Jain S, Dhingra S. Pathology of esophageal cancer and Barrett's esophagus. Annals of Cardiothoracic Surgery. Mar 2017;6:99-109. DOI: 10.21037/acs.2017.03.06

[97] Sogabe M, Okahisa T, Kimura T, et al. Influence of metabolic syndrome on upper gastrointestinal disease. Clinical Journal of Gastroenterology. Aug 2016;9:191-202. DOI: 10.1007/s12328-016-0668-1

[98] Kim YS, Kim N, Kim GH. Sex and gender differences in Gastroesophageal reflux disease. Journal of Neurogastroenterology and Motility. 30 Oct 2016;22:575-588. DOI: 10.5056/ jnm16138 
[99] Espinoza JA, Bizama C, Garcia P, et al. The inflammatory inception of gallbladder cancer. Biochimica et Biophysica Acta. Apr 2016;1865:245-254. DOI: 10.1016/j.bbcan.2016.03.004

[100] Chen Y, Liu L, Wang X, et al. Body mass index and risk of gastric cancer: A metaanalysis of a population with more than ten million from 24 prospective studies. Cancer Epidemiology, Biomarkers \& Prevention. Aug 2013;22:1395-1408. DOI: 10.1158/10559965.epi-13-0042

[101] Yang P, Zhou Y, Chen B, et al. Overweight, obesity and gastric cancer risk: Results from a meta-analysis of cohort studies. European Journal of Cancer. Nov 2009;45:2867-2873. DOI: 10.1016/j.ejca.2009.04.019

[102] Ning Y, Wang L, Giovannucci EL. A quantitative analysis of body mass index and colorectal cancer: Findings from 56 observational studies. Obesity Reviews. Jan 2010;11:19-30. DOI: 10.1111/j.1467-789X.2009.00613.x

[103] Harriss DJ, Atkinson G, George K, et al. Lifestyle factors and colorectal cancer risk (1): Systematic review and meta-analysis of associations with body mass index. Colorectal Disease. Jul 2009;11:547-563. DOI: 10.1111/j.1463-1318.2009.01766.x

[104] Althans AR, Brady JT, Keller DS, et al. Are we catching women in the safety net? Colorectal cancer outcomes by gender at a safety net hospital. American Journal of Surgery. Oct 2017;214:715-720. DOI: 10.1016/j.amjsurg.2017.07.022

[105] (IDF) IDF. Metabolic Syndrome. 2006. Available from: https://www.idf.org/e-library/ consensus-statements/60-idfconsensus-worldwide-definitionof-the-metabolic-syndrome [Accessed: 10 Oct 2017]

[106] Stuenkel CA. Menopause, hormone therapy and diabetes. Climacteric. Feb 2017;20:11-21. DOI: $10.1080 / 13697137.2016 .1267723$

[107] Traub ML. Assessing and treating insulin resistance in women with polycystic ovarian syndrome. World Journal of Diabetes. 15 Mar 2011;2:33-40. DOI: 10.4239/wjd.v2.i3.33

[108] Mauvais-Jarvis F, Clegg DJ, Hevener AL. The role of estrogens in control of energy balance and glucose homeostasis. Endocrine Reviews. Jun 2013;34:309-338. DOI: 10.1210/ er.2012-1055

[109] Hevener AL, Clegg DJ, Mauvais-Jarvis F. Impaired estrogen receptor action in the pathogenesis of the metabolic syndrome. Molecular and Cellular Endocrinology. Dec 2015;418(Pt 3):306-321. DOI: 10.1016/j.mce.2015.05.020

[110] Kim JH, Cho HT, Kim YJ. The role of estrogen in adipose tissue metabolism: Insights into glucose homeostasis regulation. Endocrine Journal. 2014;61:1055-1067

[111] Cifkova R, Krajcoviechova A. Dyslipidemia and cardiovascular disease in women. Current Cardiology Reports. Jul 2015;17:609. DOI: 10.1007/s11886-015-0609-5

[112] Park YM, Erickson C, Bessesen D, et al. Age- and menopause-related differences in subcutaneous adipose tissue estrogen receptor mRNA expression. Steroids. May 2017;121:1721. DOI: 10.1016/j.steroids.2017.03.001 
[113] Kim C. Does menopause increase diabetes risk? Strategies for diabetes prevention in midlife women. Womens Health (Lond). Mar 2012;8:155-167. DOI: 10.2217/whe.11.95

[114] Willett WC, Dietz WH, Colditz GA. Guidelines for healthy weight. The New England Journal of Medicine. 5 Aug 1999;341:427-434. DOI: 10.1056/nejm199908053410607

[115] Kuri-Morales P, Emberson J, Alegre-Diaz J, et al. The prevalence of chronic diseases and major disease risk factors at different ages among 150,000 men and women living in Mexico City: Cross-sectional analyses of a prospective study. BMC Public Health. 9 Jan 2009;9:9. DOI: 10.1186/1471-2458-9-9

[116] Salpeter SR, Walsh JM, Ormiston TM, et al. Meta-analysis: Effect of hormone-replacement therapy on components of the metabolic syndrome in postmenopausal women. Diabetes, Obesity \& Metabolism. Sep 2006;8:538-554. DOI: 10.1111/j.1463-1326.2005.00545.x

[117] Muka T, Nano J, Jaspers L, et al. Associations of steroid sex hormones and sex hormonebinding globulin with the risk of type 2 diabetes in women: A population-based cohort study and meta-analysis. Diabetes. Mar 2017;66:577-586. DOI: 10.2337/db16-0473

[118] Ding EL, Song Y, Malik VS, et al. Sex differences of endogenous sex hormones and risk of type 2 diabetes: A systematic review and meta-analysis. Journal of the American Medical Association. 15 Mar 2006;295:1288-1299. DOI: 10.1001/jama.295.11.1288

[119] Iozzo P, Lautamaki R, Borra R, et al. Contribution of glucose tolerance and gender to cardiac adiposity. The Journal of Clinical Endocrinology and Metabolism. Nov 2009;94:44724482. DOI: $10.1210 /$ jc.2009-0436

[120] McGavock JM, Lingvay I, Zib I, et al. Cardiac steatosis in diabetes mellitus: A 1H-magnetic resonance spectroscopy study. Circulation. 4 Sep 2007;116:1170-1175. DOI: 10.1161/circulationaha.106.645614

[121] Leening MJ, Ferket BS, Steyerberg EW, et al. Sex differences in lifetime risk and first manifestation of cardiovascular disease: Prospective population based cohort study. BMJ. Nov 2014;349:g5992. DOI: 10.1136/bmj.g5992

[122] Chauhan A, Moser H, McCullough LD. Sex differences in ischaemic stroke: Potential cellular mechanisms. Clinical Science (London, England). 1 Apr 2017;131:533-552. DOI: $10.1042 / \operatorname{cs} 20160841$

[123] Berglund A, Schenck-Gustafsson K, von Euler M. Sex differences in the presentation of stroke. Maturitas. May 2017;99:47-50. DOI: 10.1016/j.maturitas.2017.02.007

[124] Fortini F, Dalla V, Sega F, Caliceti C, et al. Estrogen receptor beta-dependent Notch1 activation protects vascular endothelium against tumor necrosis factor alpha (TNFalpha)induced apoptosis. The Journal of Biological Chemistry. Nov 2017;292:18178-18191. DOI: 10.1074/jbc.M117.790121

[125] van Saase JL, van Romunde LK, Cats A, et al. Epidemiology of osteoarthritis: Zoetermeer survey. Comparison of radiological osteoarthritis in a Dutch population with that in 10 other populations. Annals of the Rheumatic Diseases. 1989;48(4):271-280 
[126] Litwic A. Epidemiology and Burden of Osteoarthritis. 2013. Available from: https:// www.ncbi.nlm.nih.gov/pmc/articles/PMC3690438/ [Accessed: 2 Jan 2018]

[127] Bliddal H, Leeds AR, Christensen R. Osteoarthritis, obesity and weight loss: Evidence, hypotheses and horizons-a scoping review. Obesity Reviews. 2014;15(7):578-586. DOI: 10.1111/obr.12173

[128] Fernandes GS, Valdes AM. Cardiovascular disease and osteoarthritis: Common pathways and patient outcomes. European Journal of Clinical Investigation. 2015;45(4):405414. DOI: $10.1111 /$ eci.12413

[129] Manfredi-Lozano M, Roa J, Connecting T-SM. Metabolism and gonadal function: Novel central neuropeptide pathways involved in the metabolic control of puberty and fertility. Frontiers in Neuroendocrinology. 25 Jul 2017. DOI: 10.1016/j.yfrne.2017.07.008

[130] Yoo JH. Effects of early menarche on physical and psychosocial health problems in adolescent girls and adult women. Korean Journal of Pediatrics. Sep 2016;59:355-361. DOI: $10.3345 / \mathrm{kjp} .2016 .59 .9 .355$

[131] Chen CI, Hsu MI, Lin SH, et al. Adiponectin and leptin in overweight/obese and lean women with polycystic ovary syndrome. Gynecological Endocrinology. Apr 2015;31:264268. DOI: $10.3109 / 09513590.2014 .984676$

[132] Dewailly D. Diagnostic criteria for PCOS: Is there a need for a rethink? Best Practice \& Research. Clinical Obstetrics \& Gynaecology. Nov 2016;37:5-11. DOI: 10.1016/j. bpobgyn.2016.03.009

[133] Elghblawi E. Polycystic ovary syndrome and female reproduction. British Journal of Nursing. 11-24 Oct 2007;16:1118-1121. DOI: 10.12968/bjon.2007.16.18.27504

[134] Barbieri RL, Makris A, Randall RW, et al. Insulin stimulates androgen accumulation in incubations of ovarian stroma obtained from women with hyperandrogenism. The Journal of Clinical Endocrinology and Metabolism. May 1986;62:904-910. DOI: 10.1210/ jcem-62-5-904

[135] Witchel SF. Puberty and polycystic ovary syndrome. Molecular and Cellular Endocrinology. 25 Jul 2006;254-255:146-153. DOI: 10.1016/j.mce.2006.04.028

[136] Wallace IR, McKinley MC, Bell PM, et al. Sex hormone binding globulin and insulin resistance. Clinical Endocrinology. Mar 2013;78:321-329. DOI: 10.1111/cen.12086

[137] Belgorosky A, Baquedano MS, Guercio G, et al. Adrenarche: Postnatal adrenal zonation and hormonal and metabolic regulation. Hormone Research. 2008;70:257-267. DOI: $10.1159 / 000157871$

[138] Yura S, Ogawa Y, Sagawa N, et al. Accelerated puberty and late-onset hypothalamic hypogonadism in female transgenic skinny mice overexpressing leptin. The Journal of Clinical Investigation. Mar 2000;105:749-755. DOI: 10.1172/jci8353 
[139] LaZovic G, Radivojevic U, Milicevic S, et al. Influence of adiposity on leptin, LH and androgen levels in lean, overweight and obese PCOS patients. International Journal of Fertility and Women's Medicine. Mar-Jun 2007;52:82-88

[140] Hausmann S, Kong B, Michalski C, et al. The role of inflammation in pancreatic cancer. Advances in Experimental Medicine and Biology. 2014;816:129-151. DOI: 10.1007/ 978-3-0348-0837-8_6

[141] Nestor CC, Kelly MJ, Ronnekleiv OK. Cross-talk between reproduction and energy homeostasis: Central impact of estrogens, leptin and kisspeptin signaling. Hormone Molecular Biology and Clinical Investigation. Mar 2014;17:109-128. DOI: 10.1515/ hmbci-2013-0050

[142] Dag ZO, Dilbaz B. Impact of obesity on infertility in women. Journal of the Turkish German Gynecology Association. 2015;16:111-117. DOI: 10.5152/jtgga.2015.15232

[143] Ryan D. Obesity in women: A life cycle of medical risk. International Journal of Obesity (Lond). Nov 2007;31(Suppl 2):S3-S7; discussion S31-S32. DOI: 10.1038/sj.ijo.0803729

[144] Kumbak B, Oral E, Bukulmez O. Female obesity and assisted reproductive technologies. Seminars in Reproductive Medicine. Dec 2012;30:507-516. DOI: 10.1055/s-0032-1328879

[145] Jokela M, Elovainio M, Kivimaki M. Lower fertility associated with obesity and underweight: The US National Longitudinal Survey of youth. The American Journal of Clinical Nutrition. Oct 2008;88:886-893

[146] Gaillard R. Maternal obesity during pregnancy and cardiovascular development and disease in the offspring. European Journal of Epidemiology. Nov 2015;30:1141-1152. DOI: $10.1007 / \mathrm{s} 10654-015-0085-7$

[147] GallianoD, BellverJ. Female obesity: Short- and long-term consequences on the offspring. Gynecological Endocrinology. Jul 2013;29:626-631. DOI: 10.3109/09513590.2013.777420

[148] Black RE, Victora CG, Walker SP, et al. Maternal and child undernutrition and overweight in low-income and middle-income countries. Lancet. 3 Aug 2013;382:427-451. DOI: 10.1016/s0140-6736(13)60937-x

[149] Foo L, Tay J, Lees CC, et al. Hypertension in pregnancy: Natural history and treatment options. Current Hypertension Reports. May 2015;17:36. DOI: 10.1007/s11906-015-0545-1

[150] Garmendia ML, Zamudio C, Araya M, et al. Association between prepregnancy obesity and metabolic risk in Chilean premenopausal women 10 y postpartum. Nutrition. Jun 2017;38:20-27. DOI: 10.1016/j.nut.2017.01.003

[151] Kim C. Maternal outcomes and follow-up after gestational diabetes mellitus. Diabetic Medicine. Mar 2014;31:292-301. DOI: 10.1111/dme.12382

[152] Lee JH, Park SK, Ryoo JH, et al. U-shaped relationship between depression and body mass index in the Korean adults. European Psychiatry. 3 Jun 2017;45:72-80. DOI: 10.1016/j.eurpsy.2017.05.025 
[153] Marchi J, Berg M, Dencker A, et al. Risks associated with obesity in pregnancy, for the mother and baby: A systematic review of reviews. Obesity Reviews. Aug 2015;16:621638. DOI: $10.1111 /$ obr. 12288

[154] Torloni MR, Betran AP, Daher S, et al. Maternal BMI and preterm birth: A systematic review of the literature with meta-analysis. The Journal of Maternal-Fetal \& Neonatal Medicine. Nov 2009;22:957-970. DOI: 10.3109/14767050903042561

[155] Heslehurst N, Simpson H, Ells LJ, et al. The impact of maternal BMI status on pregnancy outcomes with immediate short-term obstetric resource implications: A metaanalysis. Obesity Reviews. Nov 2008;9:635-683. DOI: 10.1111/j.1467-789X.2008.00511.x

[156] Nkwabong E. Maternal and neonatal complications of macrosomia. Tropical Doctor. Oct 2014;44(4):201. DOI: 10.1177/0049475514539479

[157] Rougee LR, Miyagi SJ, Obstetric Obesity CAC. Is associated with neonatal hyperbilirubinemia with high prevalence in native Hawaiians and Pacific Island women. Hawai'i Journal of Medicine \& Public Health. Dec 2016;75:373-378

[158] Blomberg M. Maternal obesity, mode of delivery, and neonatal outcome. Obstetrics and Gynecology. Jul 2013;122:50-55. DOI: 10.1097/AOG.0b013e318295657f

[159] Rasmussen KM, Kjolhede CL. Prepregnant overweight and obesity diminish the prolactin response to suckling in the first week postpartum. Pediatrics. May 2004;113:e465-e471

[160] Cordero L, Oza-Frank R, Landon MB, et al. Breastfeeding initiation among macrosomic infants born to obese nondiabetic mothers. Breastfeeding Medicine. Jun 2015;10:239245. DOI: $10.1089 / \mathrm{bfm} .2015 .0028$

[161] Ramji N, Challa S, Murphy PA, et al. A comparison of breastfeeding rates by obesity class. The Journal of Maternal-Fetal \& Neonatal Medicine. Jul 2017;31:1-14. DOI: 10.1080/14767058.2017.1362552

[162] Turcksin R, Bel S, Galjaard S, et al. Maternal obesity and breastfeeding intention, initiation, intensity and duration: A systematic review. Maternal \& Child Nutrition. Apr 2014;10:166-183. DOI: 10.1111/j.1740-8709.2012.00439.x

[163] Bangasser DA, Valentino RJ. Sex differences in stress-related psychiatric disorders: Neurobiological perspectives. Frontiers in Neuroendocrinology. Aug 2014;35:303-319. DOI: 10.1016/j.yfrne.2014.03.008

[164] Moore M, Yuen HM, Dunn N, et al. Explaining the rise in antidepressant prescribing: A descriptive study using the general practice research database. British Medical Journal. 15 Oct 2009;339:b3999. DOI: 10.1136/bmj.b3999

[165] Rajan TM, Menon V. Psychiatric disorders and obesity: A review of association studies. Journal of Postgraduate Medicine. Jul-Sep 2017;63:182-190. DOI: 10.4103/jpgm. JPGM_712_16

[166] Thormann J, Chittka T, Minkwitz J, et al. Obesity and depression: An overview on the complex interactions of two diseases. Fortschritte der Neurologie-Psychiatrie. Mar 2013;81:145-153. DOI: 10.1055/s-0032-1330351 
[167] Onyike CU, Crum RM, Lee HB, et al. Is obesity associated with major depression? Results from the third National Health and nutrition examination survey. American Journal of Epidemiology. 15 Dec 2003;158:1139-1147

[168] Schmidt FM, Lichtblau N, Minkwitz J, et al. Cytokine levels in depressed and nondepressed subjects, and masking effects of obesity. Journal of Psychiatric Research. Aug 2014;55:29-34. DOI: 10.1016/j.jpsychires.2014.04.021

[169] Spahlholz J, Baer N, Konig HH, et al. Obesity and discrimination - A systematic review and meta-analysis of observational studies. Obesity Reviews. Jan 2016;17:43-55. DOI: 10.1111/obr.12343

[170] Privitera GJ, King-Shepard QW, Cuifolo KN, et al. Differential food intake and food choice by depression and body mass index levels following a mood manipulation in a buffet-style setting. Journal of Health Psychology. 1 May 2016:1359105316650508. DOI: $10.1177 / 1359105316650508$

[171] Wielopolski J, Reich K, Clepce M, et al. Physical activity and energy expenditure during depressive episodes of major depression. Journal of Affective Disorders. 15 Mar 2015;174:310-316. DOI: 10.1016/j.jad.2014.11.060

[172] Sander C, Ueck P, Mergl R, et al. Physical activity in depressed and non-depressed patients with obesity. Eating and Weight Disorders. 10 Feb 2017. DOI: 10.1007/ s40519-016-0347-8

[173] Generelo E, Zaragoza J, Julian JA, et al. Physical activity patterns in normal-weight adolescents on week-days and week-ends. The Journal of Sports Medicine and Physical Fitness. Dec 2011;51:647-653

[174] Hamrik Z, Sigmundova D, Kalman M, et al. Physical activity and sedentary behaviour in Czech adults: Results from the GPAQ study. European Journal of Sport Science. 2014;14:193-198. DOI: 10.1080/17461391.2013.822565

[175] Micklesfield LK, Pedro TM, Kahn K, et al. Physical activity and sedentary behavior among adolescents in rural South Africa: Levels, patterns and correlates. BMC Public Health. 16 Jan 2014;14:40. DOI: 10.1186/1471-2458-14-40

[176] UK P. Women and Sport. 2014. Available from: https://publications.parliament.uk/pa/ cm201415/cmselect/cmcumeds/513/513.pdf [Accessed: 3 Oct 2017]

[177] Zhang J, Yen ST. Physical activity, gender difference, and depressive symptoms. Health Services Research. Oct 2015;50:1550-1573. DOI: 10.1111/1475-6773.12285

[178] Simoni-Wastila L. The use of abusable prescription drugs: The role of gender. Journal of Women's Health \& Gender-Based Medicine. Apr 2000;9:289-297. DOI: 10.1089/152460900318470

[179] Pratt LA, Brody DJ, Antidepressant GQ. Use in persons aged 12 and over: United States, 2005-2008. NCHS Data Brief. Oct 2011:1-8

[180] Himmerich H, Minkwitz J, Kirkby KC. Weight gain and metabolic changes during treatment with antipsychotics and antidepressants. Endocrine, Metabolic \& Immune Disorders Drug Targets. 2015;15:252-260 
[181] Steinig J, Nagl M, Linde K, et al. Antenatal and postnatal depression in women with obesity: A systematic review. Archives of Women's Mental Health. Aug 2017;20:569585. DOI: 10.1007/s00737-017-0739-4

[182] Hall MH, Kline CE, Nowakowski S. Insomnia and sleep apnea in midlife women: prevalence and consequences to health and functioning. F1000Prime Reports. 2015;7:63. DOI: $10.12703 / \mathrm{p} 7-63$

[183] Gariepy G, Nitka D, Schmitz N. The association between obesity and anxiety disorders in the population: A systematic review and meta-analysis. International Journal of Obesity. Mar 2010;34:407-419. DOI: 10.1038/ijo.2009.252

[184] Zedler B, von Lengerke T, Emeny R, et al. Obesity and symptoms of depression and anxiety in pre- and postmenopausal women: A comparison of different obesity indicators. Psychotherapie, Psychosomatik, Medizinische Psychologie. Mar 2014;64:128-135. DOI: 10.1055/s-0033-1349097

[185] Bromberger JT, Kravitz HM, Chang Y, et al. Does risk for anxiety increase during the menopausal transition? Study of women's health across the nation. Menopause. May 2013;20:488-495. DOI: 10.1097/GME.0b013e3182730599

[186] NHS. Adult Psychiatric Morbidity Survey. 2014. Available from: http://content.digital. nhs.uk/catalogue/PUB21748/apms-2014-ptsd.pdf [Accessed: 4 Oct 2017]

[187] Bartoli F, Crocamo C, Alamia A, et al. Posttraumatic stress disorder and risk of obesity: Systematic review and meta-analysis. The Journal of Clinical Psychiatry. Oct 2015; 76:e1253-e1261. DOI: 10.4088/JCP.14r09199

[188] Ford ME, Magwood G, Brown ET, et al. Disparities in obesity, physical activity rates, and breast cancer survival. Advances in Cancer Research. 2017;133:23-50. DOI: 10.1016/ bs.acr.2016.08.002

[189] Masodkar K, Johnson J, Peterson MJ. A review of posttraumatic stress disorder and obesity: Exploring the link. The Primary Care Companion for CNS Disorders. 7 Jan 2016;18(1). DOI: 10.4088/PCC.15r01848. eCollection 2016

[190] Yaffe K, Falvey C, Harris TB, et al. Effect of socioeconomic disparities on incidence of dementia among biracial older adults: Prospective study. British Medical Journal. 19 Dec 2013;347:f7051. DOI: 10.1136/bmj.f7051

[191] Podcasy JL, Epperson CN. Considering sex and gender in Alzheimer disease and other dementias. Dialogues in Clinical Neuroscience. Dec 2016;18:437-446

[192] Matthews FE, Arthur A, Barnes LE, et al. A two-decade comparison of prevalence of dementia in individuals aged 65 years and older from three geographical areas of England: Results of the cognitive function and ageing study I and II. Lancet. 26 Oct 2013;382:1405-1412. DOI: 10.1016/s0140-6736(13)61570-6

[193] Society AS. Dementia Alzheimer UK. 2014. Available from: https://www.alzheimers. org.uk/download/downloads/id/2323/dementia_uk_update.pdf [Accessed: 5 Oct 2017] 
[194] Xu WL, Atti AR, Gatz M, et al. Midlife overweight and obesity increase late-life dementia risk: A population-based twin study. Neurology. 3 May 2011;76:1568-1574. DOI: 10.1212/ WNL.0b013e3182190d09

[195] Wotton CJ, Goldacre MJ. Age at obesity and association with subsequent dementia: Record linkage study. Postgraduate Medical Journal. Oct 2014;90:547-551. DOI: 10.1136/ postgradmedj-2014-132571

[196] Cunningham C. Microglia and neurodegeneration: The role of systemic inflammation. Glia. Jan 2013;61:71-90. DOI: 10.1002/glia.22350

[197] Buysse DJ. Insomnia. Journal of the American Medical Association. 20 Feb 2013;309:706716. DOI: $10.1001 /$ jama.2013.193

[198] Mai E, Buysse DJ. Insomnia: Prevalence, impact, pathogenesis, differential diagnosis, and evaluation. Sleep Medicine Clinics. 2008;3:167-174. DOI: 10.1016/j.jsmc.2008.02.001

[199] Zhang B, Wing YK. Sex differences in insomnia: A meta-analysis. Sleep. Jan 2006;29:85-93

[200] Wu HB, Wang H, Hu RY, et al. The association between sleep duration, snoring and prevalent type 2 diabetes mellitus with regard to gender and menopausal status: The CKB study in Zhejiang rural area, China. Acta Diabetologica. Jan 2017;54:81-90. DOI: 10.1007/s00592-016-0918-1

[201] Markwald RR, Melanson EL, Smith MR, et al. Impact of insufficient sleep on total daily energy expenditure, food intake, and weight gain. Proceedings of the National Academy of Sciences of the United States of America. 2 Apr 2013;110:5695-5700. DOI: 10.1073/pnas.1216951110

[202] Spaeth AM, Dinges DF, Goel N. Effects of experimental sleep restriction on weight gain, caloric intake, and meal timing in healthy adults. Sleep. 1 Jul 2013;36:981-990. DOI: $10.5665 /$ sleep. 2792

[203] Buxton OM, Marcelli E. Short and long sleep are positively associated with obesity, diabetes, hypertension, and cardiovascular disease among adults in the United States. Social Science \& Medicine. Sep 2010;71:1027-1036. DOI: 10.1016/j.socscimed.2010.05.041

[204] Drager LF, Togeiro SM, Polotsky VY, et al. Obstructive sleep apnea: A cardiometabolic risk in obesity and the metabolic syndrome. Journal of the American College of Cardiology. 13 Aug 2013;62:569-576. DOI: 10.1016/j.jacc.2013.05.045

[205] Tuomilehto H, Seppa J, Uusitupa M. Obesity and obstructive sleep apnea - Clinical significance of weight loss. Sleep Medicine Reviews. Oct 2013;17:321-329. DOI: 10.1016/j. smrv.2012.08.002

[206] Panossian LA, Veasey SC. Daytime sleepiness in obesity: Mechanisms beyond obstructive sleep apnea - A review. Sleep. 1 May 2012;35:605-615. DOI: 10.5665/sleep.1812 
[207] Weschenfelder J, Sander C, Kluge M, et al. The influence of cytokines on wakefulness regulation: Clinical relevance, mechanisms and methodological problems. Psychiatria Danubina. Jun 2012;24:112-126

[208] Mantua J, Spencer RM. The interactive effects of nocturnal sleep and daytime naps in relation to serum C-reactive protein. Sleep Medicine. Oct 2015;16:1213-1216. DOI: 10.1016/j. sleep.2015.06.014

[209] Al-Safi ZA, Polotsky AJ. Obesity and menopause. Best Practice \& Research. Clinical Obstetrics \& Gynaecology. May 2015;29:548-553. DOI: 10.1016/j.bpobgyn.2014.12.002 
